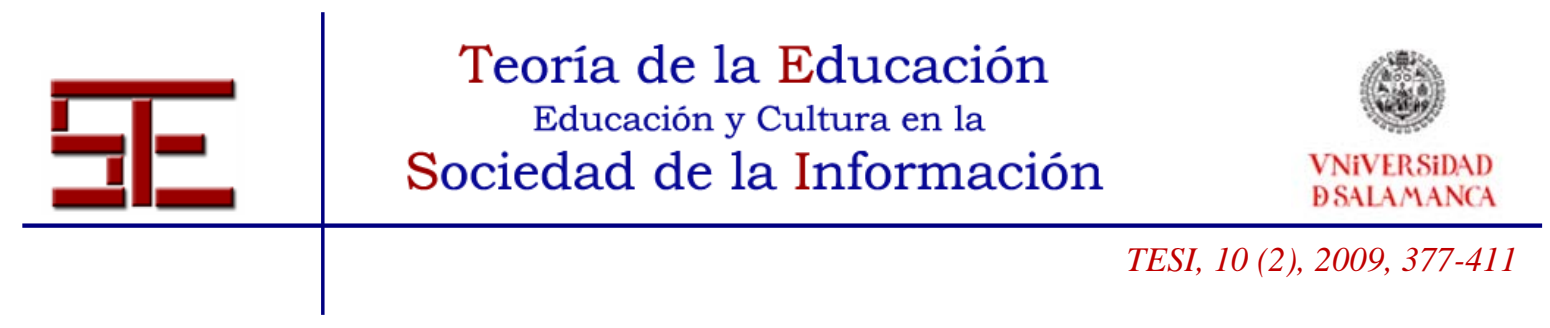

\title{
LOS ALUMNOS ERASMUS EN LA TORRE DE BABEL. EL APRENDIZAJE DE LENGUAS EXTRANJERAS BASADO EN LAS COMPETENCIAS COMUNICATIVAS Y EN EL USO DE LAS TIC.
}

Resumen. Más de un millón de estudiantes en Europa han tenido la posibilidad de intercambiar vida universitaria en otros centros europeos de educación superior, abriendo inmensas perspectivas de conocimiento, relaciones culturales y comunicativas. Con la movilidad de alumnos y profesores, Europa afianza, en la práctica, su identidad en un universo global. Este trabajo presenta los resultados de un análisis de las competencias comunicativas y el uso de las Tecnologías de la Información y de la Comunicación de estudiantes de intercambio alemanes. Los datos se obtuvieron a partir de dos cuestionarios que realizaron 20 estudiantes del Romanisches Seminar de la Universität Bonn, cuya lengua nativa es el alemán y su segunda lengua extranjera el español. En términos generales, los resultados confirman que la estancia de seis meses en un país de hablan hispana incrementa, en primer lugar, las competencias comunicativas en la lengua española y, además, el uso de las TIC en lenguas extranjeras.

Palabras clave: Programa Erasmus, Espacio Europeo de Educación Superior (EEES), español como lengua extranjera, competencias comunicativas, uso de las Tecnologías de la Comunicación y la Información (TIC), multiculturalidad, multilingüismo.

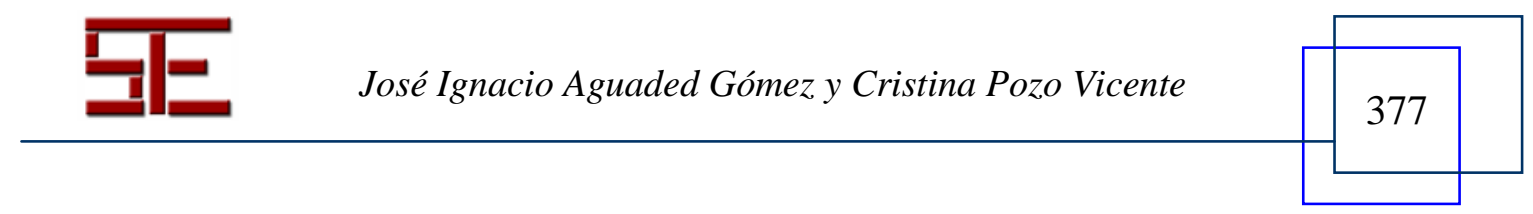




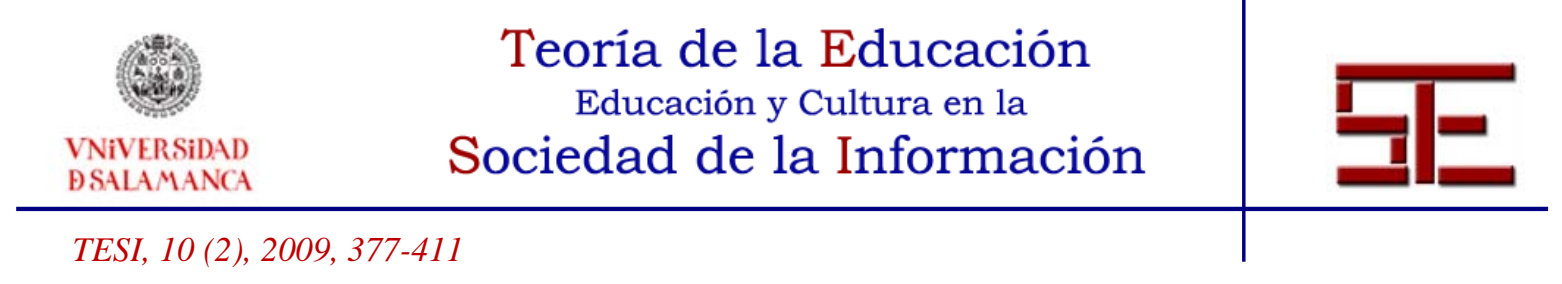

\title{
ERASMUS STUDENTS IN THE TOWER OF BABEL. FOREIGN LANGUAGE LEARNING BASED ON COMMUNICATIVE COMPETENCIES AND THE USE OF ICT.
}

\begin{abstract}
So far more than one million European students have had the possibility to study at other higher education institutions in Europe; this has opened immense perspectives for cultural and communicative knowledge and relationships. Europe consolidates, in practice, its identity in a global universe through mobility. This article presents the results regarding the communicative competencies and the use of Information and

Communication Technologies (ICT) of German exchange students. The data was extracted from two e378xhaustive, rigorous and methodical questionnaires related to communicative and ICT competencies completed by 20 exchange students from Romanisches Seminar of the Universität Bonn, their native language being German and learning Spanish as a foreign language. Generally, the results confirm that a stay in a foreign country increases the use of ICT and widely improves German native speakers' communicative competencies in Spanish.
\end{abstract}

Keywords: Erasmus program, European Higher Education Area (EHEA), Spanish as a foreign language, communicative competencies, use of Information and Communication Technologies (ICT), ICT competencies, multiculturalism, multilinguism.

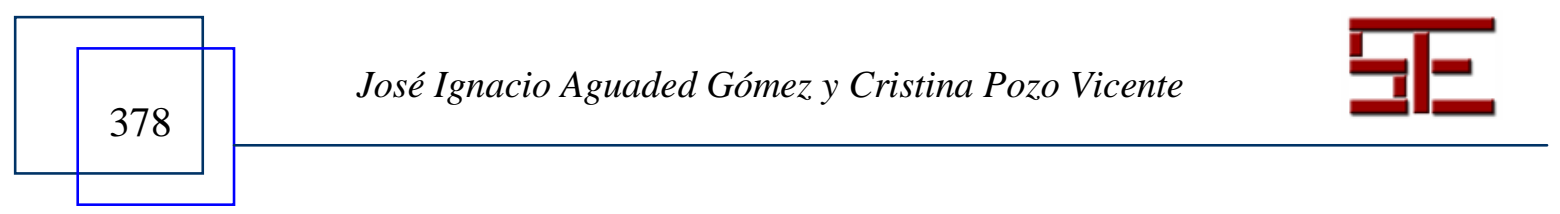




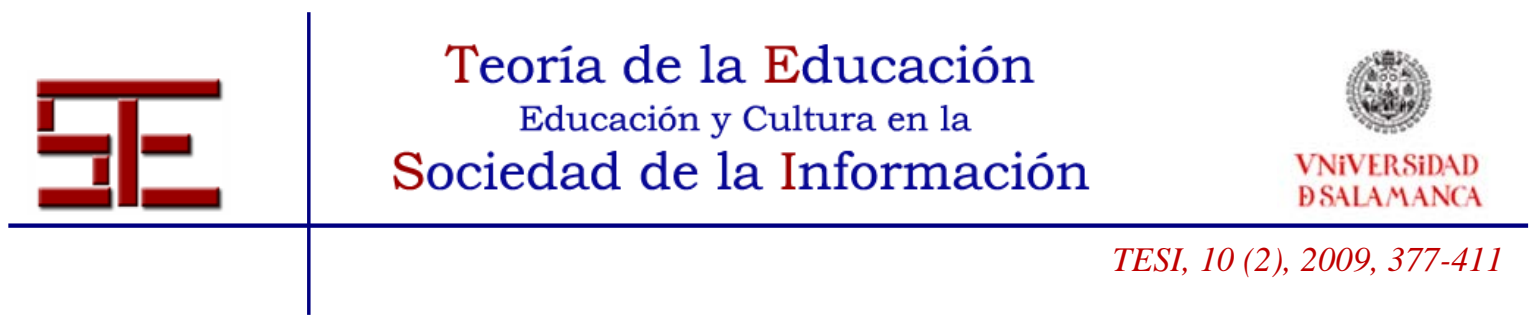

\section{LOS ALUMNOS ERASMUS EN LA TORRE DE BABEL. EL APRENDIZAJE DE LENGUAS EXTRANJERAS BASADO EN LAS COMPETENCIAS COMUNICATIVAS Y EN EL USO DE LAS TIC.}

José Ignacio Aguaded Gómez, vicerrector.tecnologias@uhu.es Universidad de Huelva.

Cristina Pozo Vicente

cristina.pozo@uni-bonn.de

Universität Bonn.

\section{Introducción}

Este artículo abarca un estudio teórico y empírico de aspectos referentes al fenómeno Erasmus, basado en un enfoque pedagógico socio-constructivista. En primer lugar, se presenta un marco teórico que describe la situación actual de la educación superior en Europa, básicamente, se habla de las competencias comunicativas, del enfoque por tareas, de las TIC y del aprendizaje de lenguas. Al estudio teórico le sigue el estudio empírico centrado en el análisis de las competencias comunicativas y del uso de las TIC de los estudiantes Erasmus antes y después de su estancia en el extranjero. El análisis de los resultados del estudio empírico comparándolo con las hipótesis presentadas en el apartado de la investigación (1.2) ponen de manifiesto la importancia que tiene la estancia en el extranjero tanto para el presente como para el futuro desarrollo de una sociedad plurilingüe y con conocimientos en nuevas tecnologías, principalmente en la red. El artículo tiene por objetivo presentar un fenómeno iniciado hace más de dos décadas, pero que en la actualidad ha tomado su máximo auge: el programa de movilidad europea

Erasmus.

\section{MARCO TEÓRICO}

\subsection{Las lenguas en el escenario del Espacio Europeo de Educación Superior}

A lo largo de la historia, la humanidad ha utilizado el lenguaje como vehículo de comunicación y de interrelación con sus semejantes para describir, analizar y comentar experiencias y acontecimientos. Sin embargo, en un mundo globalizado y de internet

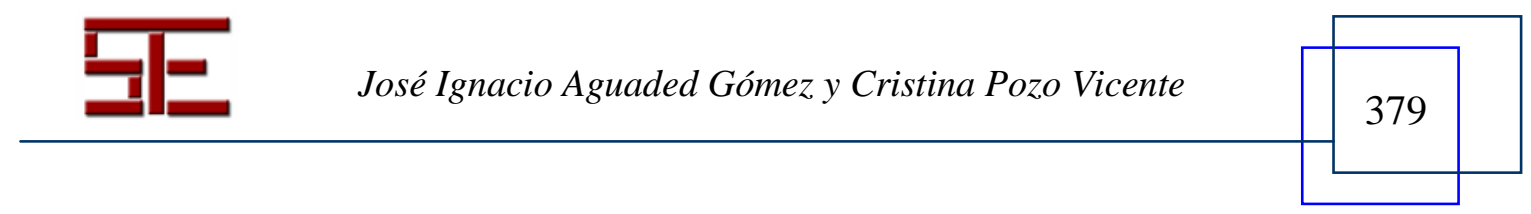




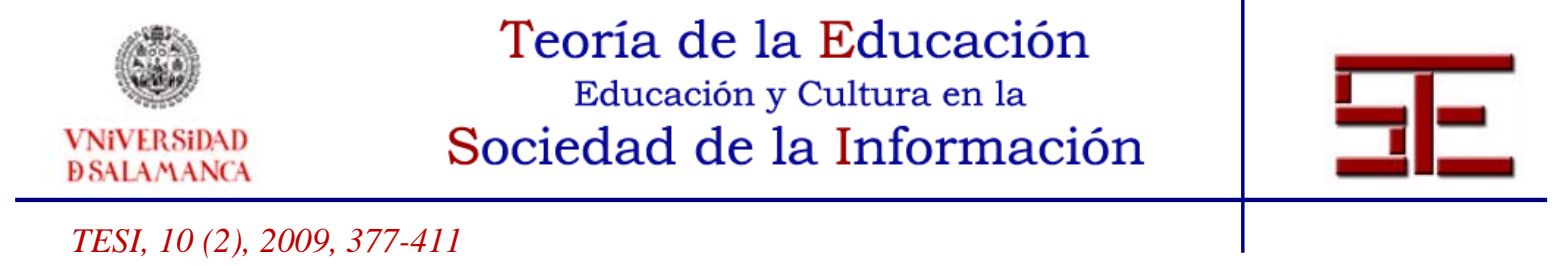

como el actual, las competencias comunicativas de los ciudadanos cobran aún más importancia. El aprendizaje de más de dos lenguas extranjeras no es un fenómeno aislado, aunque durante la última década las instituciones educativas, sobre todo, las de educación superior, están invirtiendo un gran número de esfuerzos en impulsar su aprendizaje y saldar las deficiencias, financiando programas de movilidad como Erasmus.

La educación superior constituye una pieza clave en la formación de ciudadanos, en tanto que capacita de recursos humanos cualificados a los estados, y se reconoce como uno de los mecanismos básicos de los que dispone nuestra sociedad para afrontar los nuevos retos y desafíos del progreso social. En una sociedad global, la celeridad con la que evolucionan los medios de transmisión del conocimiento exige a las instituciones de educación superior actualizarse, renovar instrumentos y mecanismos, y adoptar nuevas metodologías comprometidas en crear un canal de acceso al aprendizaje permanente. Es necesario que la educación superior avance en ese sentido si quiere mantener el rol que le corresponde en el desarrollo cultural y social y en la formación continua de recursos humanos coherente a su tradición y a sus potencialidades. Por lo tanto, nos encontramos ante un nuevo sistema de transmisión del saber en la sociedad del conocimiento en el que las instituciones de educación superior tienen que superar las fronteras, estimular la interacción entre estudiantes y docentes de distintas universidades del mundo, internacionalizar la cultura y el saber, fomentar el aprendizaje de lenguas extranjeras, y crear una universidad abierta y democrática, capaz de elaborar nuevos conocimientos pero también nuevos valores.

A mediados de los años cincuenta, en la UE se comenzaron a detectar necesidades, sobre todo de índole económica, que generaban una interdependencia creciente entre los países miembros, por lo que se adoptaron medidas políticas que fomentaran la actividad de los mercados europeos. Tras el éxito de la Comunidad Económica Europea (CEE), se iniciaron planes, cuya finalidad era abarcar también la dimensión social y educativa de los países miembros de la UE, surgiendo proyectos como Erasmus, hoy en día un éxito en el ámbito de la educación superior principalmente por su dimensión interlingüística e intercultural.

En ese contexto, el plurilingüismo y las Tecnologías de la Información y la Comunicación (TIC) se presentan como factores fundamentales que intervienen en el proceso de convergencia en los diferentes sistemas universitarios europeos. Así lo han entendido las instituciones políticas europeas y las propias universidades, quienes además hacen hincapié en la necesidad de un aprendizaje a lo largo de la vida (lifelong

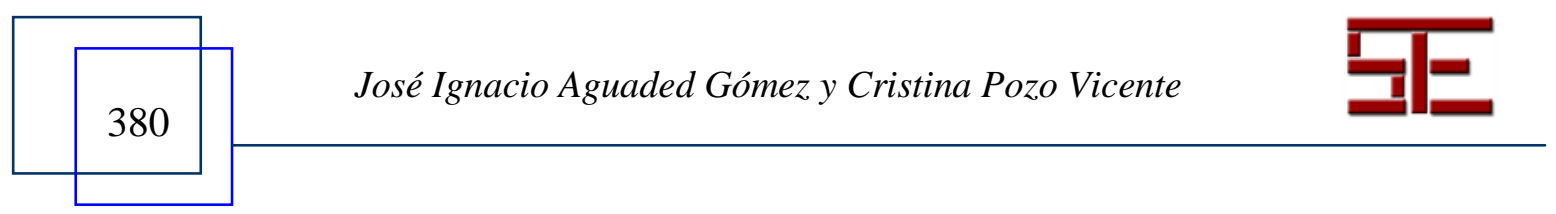




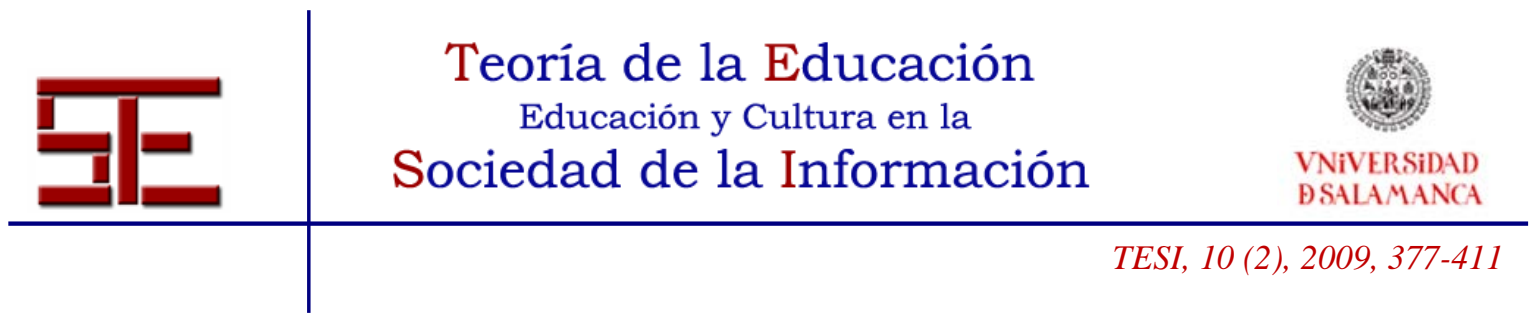

learning), la movilidad de los ciudadanos y las TIC como factores clave en la didáctica de las lenguas y en la propagación de las culturas. El uso y aplicación de las TIC permite poder consultar, buscar información y comunicarnos a cualquier hora y en cualquier lugar sin limitaciones temporales ni espaciales, lo que deja la puerta abierta para imaginarnos un contexto de enseñanza superior nuevo en el que los estudiantes amplíen sus conocimientos en esas nuevas tecnologías.

Sin embargo, las TIC obligan a los docentes, como principales impulsores del aprendizaje, a reciclarse y a actualizarse, lo que les lleva a replantearse la estructura de asigna tura así como la dinámica y la administración del tiempo y del espacio. Los docentes tienen que entender que entre la educación y las TIC se establecen sinergias conjuntas y, por eso, necesitan entender el nuevo código y el lenguaje que aportan esas nuevas tecnologías. Para los estudiantes, sobre todo, para los que participan en un programa de intercambio, las TIC constituyen una herramienta de comunicación y de búsqueda de información de un gran potencial.

El programa de movilidad Erasmus, impulsado por la Comisión Europea, se ha convertido en uno de los promotores principales del cambio en la educación superior, ya que contribuye a reconfigurar los sistemas universitarios en Europa inspirados en el Proceso de Bolonia, un proyecto ambicioso y de gran envergadura que pretende simplificar los sistemas educativos europeos de los 45 países participantes. El programa Erasmus incluye una amplia gama de medidas, diseñadas principalmente para apoyar actividades transnacionales en instituciones y organizaciones de enseñanza superior para promover la movilidad y el intercambio de su personal docente y de sus estudiantes.

\subsection{La competencia comunicativa y el enfoque por tareas}

El MCERL (Marco Común Europeo de Referencia para Lenguas) se basa en el enfoque lingüístico denominado comunicativo y/o funcional. Ese enfoque surge a partir de la década de los setenta y se fundamenta en el aprendizaje de la lengua basado en las necesidades comunicativas reales y presenta un carácter integrador que combina el uso de las habilidades de la lengua a partir de una situación o contexto comunicativo.

En cuanto al enfoque comunicativo y/o funcional, diversos autores (Hymes 1972b; 1973; Munby 1978; Canale \& Swain 1980; Savignon 1983; Canale 1983) definen la

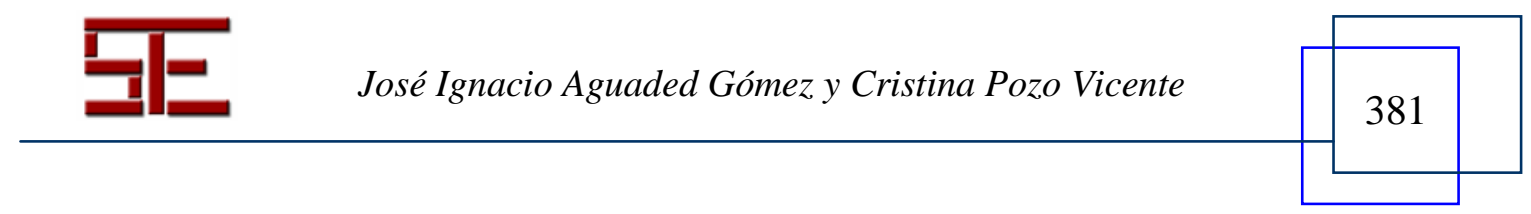




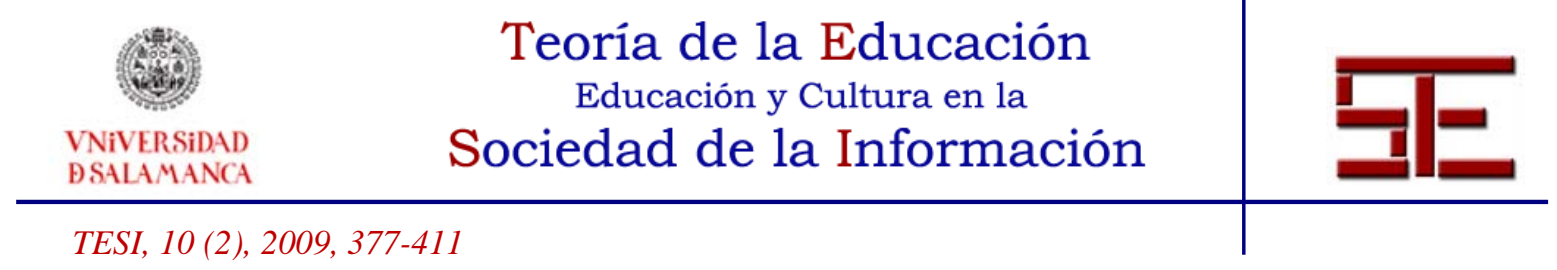

competencia comunicativa como la habilidad de usar la lengua comunicativamente, eso significa utilizar el conocimiento y la capacidad de implementar o usar esa competencia (Widdowson 1983). Candlin (1986: 40) describe la competencia comunicativa como: «la habilidad de crear significados explorando el potencial inherente en cualquier lengua en continua modificación y en respuesta al cambio, negociando el valor de la convención y estableciendo un conjunto de procedimientos para adaptar ese conocimiento a la resolución de nuevos problemas de comunicación». A comienzos de los años, 1960 Lado $(1961)$ y Carrol $(1963,1968)$ propusieron un marco para medir la competencia en lengua. Esos modelos se basaban en la distinción de las competencias (comprensión auditiva, expresión oral, comprensión lectora y expresión escrita) de los componentes del conocimiento como la gramática, el vocabulario, la fonología y la grafología, pero no explicaban la relación entre el conocimiento y las habilidades o competencias. Halliday (1976) afirma, en su descripción sobre la lengua, que existe tanto la función textual como la elocutiva, mientras que Van Dijk defiende el contexto del discurso y la inseparable relación entre el texto y el contexto. Por su parte, Hymes (1972, 1974, 1982) considera que los factores socioculturales están implicados en la conversación. Todos esos modelos demuestran que hay una concepción ampliamente extendida de la competencia en lengua que reconoce la importancia del contexto más allá de la frase al uso apropiado de la lengua.

En modelos recientes sobre competencias comunicativas y sobre las habilidades y las competencias que se requieren en el uso de la lengua (Savignon, 1983; Kramsch, 1986) se presentan la lengua como un proceso dinámico de integración del conocimiento, de las reglas gramaticales, y cómo hay que usarla para que responda a los objetivos comunicativos. Bachman y Palmer (1996) dieron un paso adelante analizando los componentes de la lengua, los que denominaron «competencias comunicativas». Estos dos autores clasifican las competencias en dos tipos: competencia organizacional y pragmática, formadas cada una por diferentes categorías. Bachman (1990) define el marco teórico que mejora los modelos anteriores: aporta bases para describir cómo medir la competencia lingüística e intenta caracterizar el proceso en el que los diferentes componentes interactúan con el contexto. Estos tres componentes en el marco de la communicative language abilities (CLA) son: la competencia lingüística, la competencia estratégica y los mecanismos psicofisiológicos. La competencia lingüística contempla el conjunto de conocimientos que se emplean en la comunicación, mientras que la competencia estratégica es la capacidad mental para utilizar los elementos lingüísticos en un contexto comunicativo y los medios para aplicar competencias lingüísticas a una situación de comunicación real. Los mecanismos psicofisiológicos se

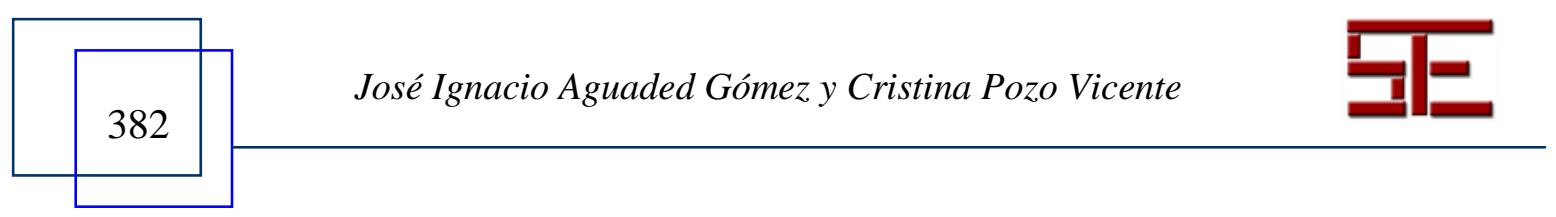




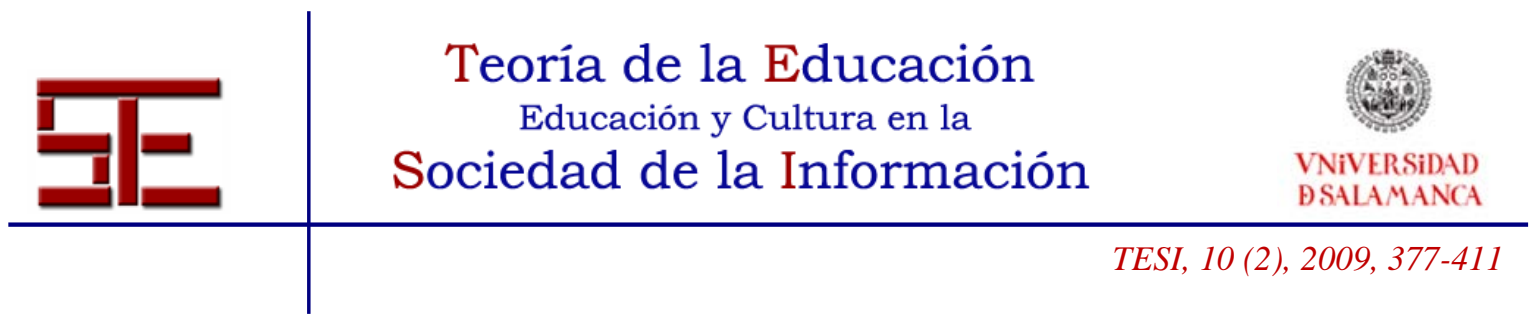

refieren a los procesos físicos, neuronales y psicológicos que tienen lugar o se producen durante la interacción (sonido, luz, etc.).

Los estudios y las teorías en el campo de la lingüística contribuyen, indudablemente, a la didáctica y al aprendizaje de una lengua, sobre todo, en la enseñanza de la lengua extranjera y en el contexto de la internacionalización y del EEES. El paradigma de las competencias comunicativas, un concepto desarrollado por la lingüística, ha creado tendencias pedagógicas aplicadas al aprendizaje de lenguas como el denominado enfoque por tareas. La base metodológica del aprendizaje de lengua extranjera, por tareas, se fundamenta en las teorías lingüísticas comunicativas o funcionales, pero también en los enfoques educativos constructivistas actuales.

El MCERL se basa en el enfoque comunicativo, pero también en los actos del habla; se orienta en la acción y considera a los usuarios y a los alumnos agentes sociales, que tienen que llevar a cabo «tareas» a realizar en un contexto determinado y en un campo de acción. Los actos del habla forman parte de una actividad lingüística, pero también tienen su función en un contexto social. Las «tareas» son acciones que llevan a cabo los individuos mediante el uso del lenguaje $y$, para ello, emplean sus competencias comunicativas para conseguir un resultado específico como puede ser la resolución de problemas, el acatamiento de una obligación o el logro de un objetivo. Este enfoque, basado en la acción, tiene en cuenta las competencias generales y específicas del individuo y sus recursos cognitivos y emocionales. En ese contexto, el aprendizaje de la lengua se entiende como: el uso de la lengua como un aprendizaje que comprende las acciones que realizan las personas, como individuos y como agentes sociales, y que desarrollan una serie de competencias, tanto generales como comunicativas y lingüísticas. Las personas cuando realizan diferentes tareas de lengua aplican sus competencias lingüísticas y adoptan las estrategias más apropiadas al contexto, al texto y al proceso, tanto comprensivo como expresivo (MCERL, 2002).

Las teorías expuestas con anterioridad definen las diferentes formas de la competencia comunicativa y desde un enfoque principalmente lingüístico. Dentro del ámbito del aprendizaje de la lengua extranjera, consideramos que ese aprendizaje tiene que ir acompañado de la adquisición de una competencia pluricultural, es decir, su capacidad para poder participar en la cultura y comunicarse en su lengua con una actitud tolerante y respetuosa. Existe una relación inseparable entre lengua y cultura y viceversa y, por eso, en la comunidad hablante, la adquisición de una lengua no se puede contemplar como un fenómeno externo a la cultura. La lengua empleada en un contexto real por los

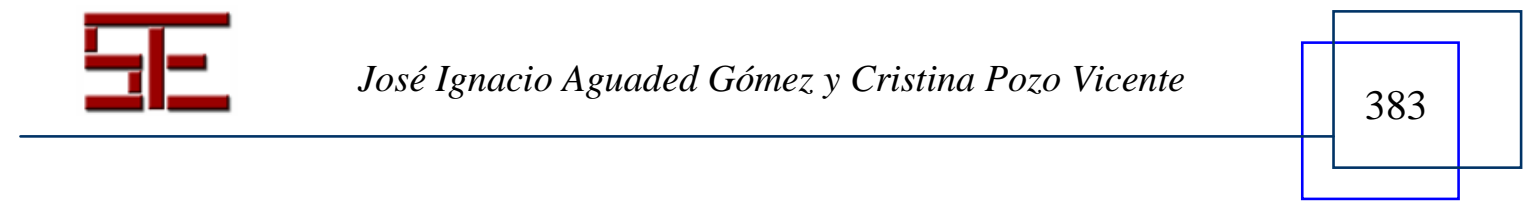




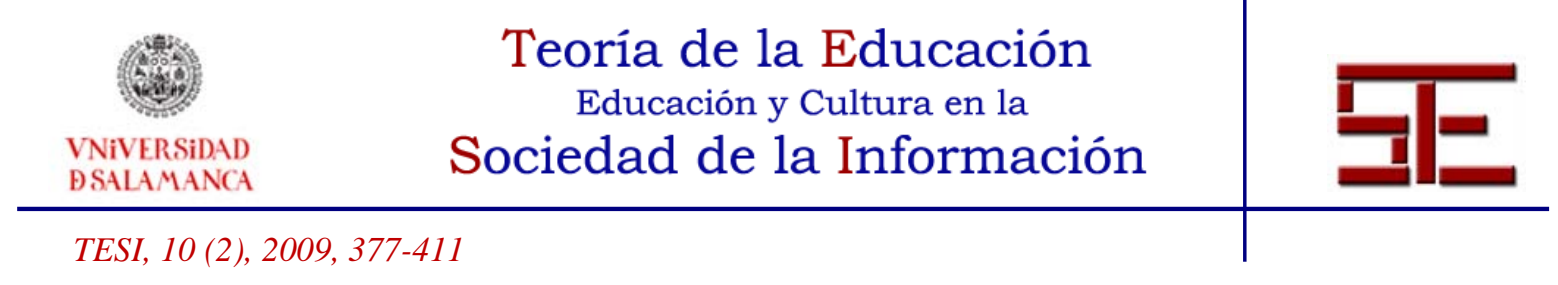

estudiantes de lengua L2 no solo favorece el aprendizaje de la lengua y la cultura sino también la adquisición de valores éticos como la tolerancia y el respeto hacia otras culturas y formas de vida. Por lo tanto, podemos concluir que el aprendizaje de una lengua en un contexto real, como es la estancia Erasmus, favorece la adquisición de la lengua extranjera, de su cultura y de valores éticos que ayudan a la construcción de la Europa multilingüe y multicultural. Además, la estancia Erasmus permite entrar en contacto con otros alumnos de otros países, por lo que los estudiantes tienen la oportunidad de conocer otras lenguas, culturas y formas de pensar.

En nuestra investigación, el MCERL se emplea como una herramienta para evaluar la evolución de los procesos de adquisición de lenguas en un contexto de aprendizaje especial, fuera del aula. Se aborda la adquisición de la competencia comunicativa y pluricultural haciendo hincapié en el contexto real en el que se produce el aprendizaje.

\subsection{Las TIC y el aprendizaje de lenguas}

El entorno tecnológico ha de consolidar la capacidad comunicativa en una nueva dimensión; el objetivo sería no priorizar la facultad humana de comunicar ni la disciplina de la lengua, como saber organizado, sino en el desarrollo de la potencialidad lingüística y la adaptación a las nuevas exigencias de la sociedad (Pérez y Aguaded, 1994). El desarrollo de las competencias comunicativas debe estar acompañado de unas estrategias comunicativas y semiológicas, diferentes a las tradicionales, que se adapten a los códigos actuales y lenguajes en contextos tecnológicos, y a las novedosas formas de selección, tratamiento e interpretación de la información; de manera que la competencia lingüístico- tecnológica permita al hablante desenvolverse con autonomía en lo que ya se denomina un «mundo cibernético virtual» (Casals y Lorenzo, 1997: 1142). Según Aguaded y Pérez (2001: 126), se perfila un imprescindible proceso de reconversión docente estrechamente ligado a los cambios que se van originando en nuestra sociedad conforme se va generalizando el uso de las nuevas tecnologías».

Los entornos tecnológicos son ideales para desarrollar y llevar a cabo prácticas de interacción e intercambio comunicativo. Eso contribuye a desarrollar la competencia comunicativa que necesita servirse de prácticas flexibles, abiertas y reales, tanto en el aula como en el espacio virtual. Esas prácticas pueden ser inmediatas entre estudiantes procedentes de diferentes cursos, países, etc., o simuladas y asincrónicas. «Mediante los programas informáticos interactivos se producen situaciones comunicativas reales, en las que el alumno, en interacción con el programa pone en práctica sus habilidades lingüísticas para llevar a cabo auténticos intercambios comunicativos de forma

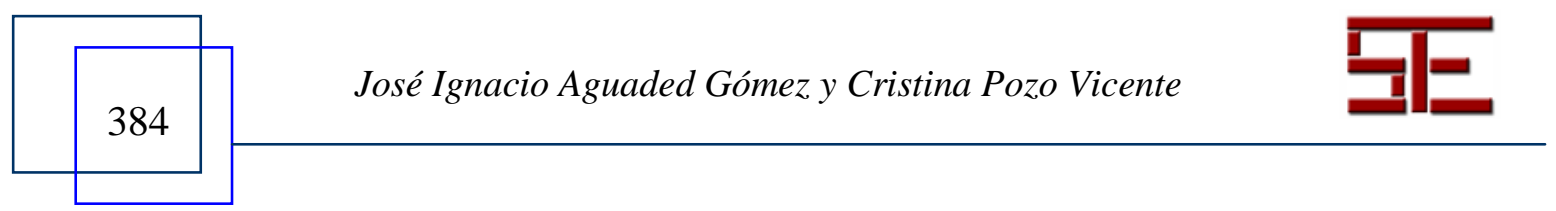




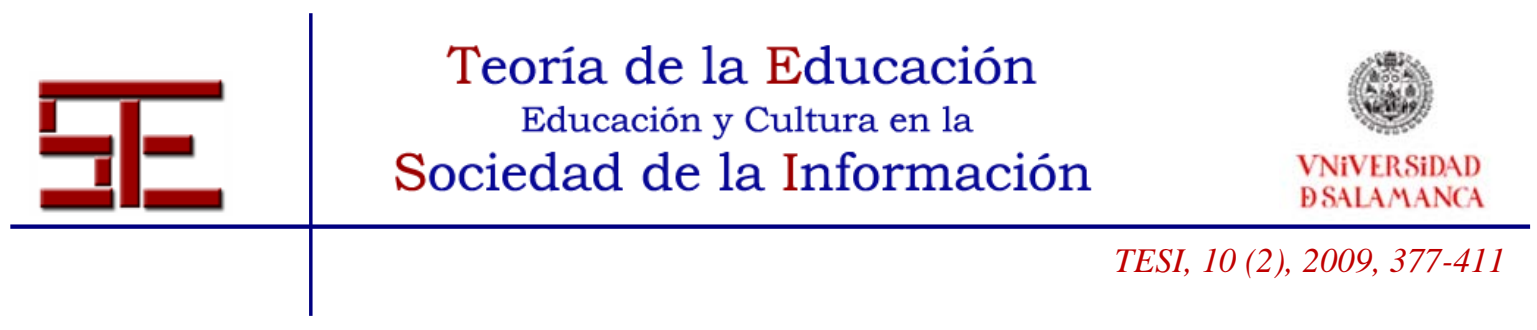

motivadora» (Prado Aragonés, 2001: 24). El uso de los recursos tecnológicos mejora las habilidades discursivas escritas, facilita la producción y corrección de textos de forma sencilla y rápida y permite conocer tipologías de textos y trabajar habilidades como la concisión, la flexibilidad y la brevedad. Entre los servicios o recursos tecnológicos caben destacar: los foros o grupos de noticias que permiten la discusión y el intercambio de opiniones; los chats, la videoconferencia o el correo electrónico. En este punto, cabe subrayar que la tecnología permite la comunicación oral y escrita.

El uso de las nuevas tecnologías no tiene nunca que sustituir a la comunicación directa y real en el aula, sino que ambas tienen que ser compatibles y aplicadas como un instrumento fundamental para motivar y facilitar el aprendizaje. Los individuos tienen que «conocer esos nuevos lenguajes, apropiarse de ellos, comprenderlos juiciosamente, consumirlos inteligentemente, hacer usos creativos con los mismos, pero también es prioritario el conocimiento de los medios como hecho comunicativo» (Aguaded y Pérez, 2001: 120). La enseñanza mediante la tecnología informática y telemática permite una enseñanza activa, flexible y personalizada -acorde con los ritmos de aprendizaje y necesidades educativas- que supera los obstáculos espacio-temporales, es decir, un entorno comunicativo sin precedentes. Ese nuevo entorno tecnológico fomenta la interacción, el trabajo cooperativo, la interdisciplinariedad y permite un conocimiento más global de la realidad y una proyección plurilingüística e intercultural.

En el nuevo ámbito de la sociedad de la comunicación es necesario adquirir conocimientos y desarrollar destrezas y capacidades acorde a los nuevos tiempos. Actualmente, las capacidades necesarias superan la competencia comunicativa (Bachman, 1990); constituyen un concepto de competencia más extenso que la competencia lingüística; abarca la competencia pragmática y los mecanismos psicofisiológicos: la competencia hipertextual (Andrea, 2000). Según Aguaded y Pérez (2001), el aprendizaje se basa en el desarrollo de conceptos y actitudes, pero también en el fomento de técnicas y procedimientos que permitan a los alumnos un uso adecuado de los nuevos recursos tecnológicos y un tratamiento crítico de la información: el conocimiento de nuevos códigos multimedia en interacción con códigos lingüísticos tradicionales; las estrategias para la búsqueda, selección, organización y tratamiento de la información; las habilidades de lectura y comprensión de la información, expresión y elaboración apropiada a los nuevos formatos hipertextuales; el espíritu crítico que permita la selección de la información; la capacidad de autonomía y autogestión en el proceso de aprendizaje; la habilidad para la interacción, la participación activa y la toma inmediata de decisiones; el espíritu abierto, plurilingüe y pluricultural que permita la

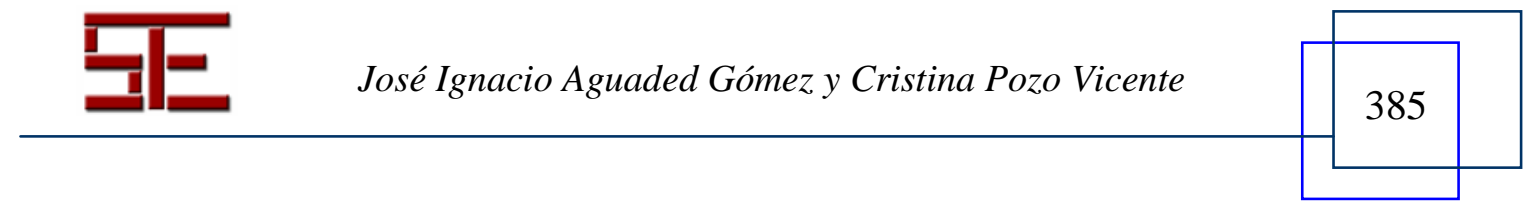




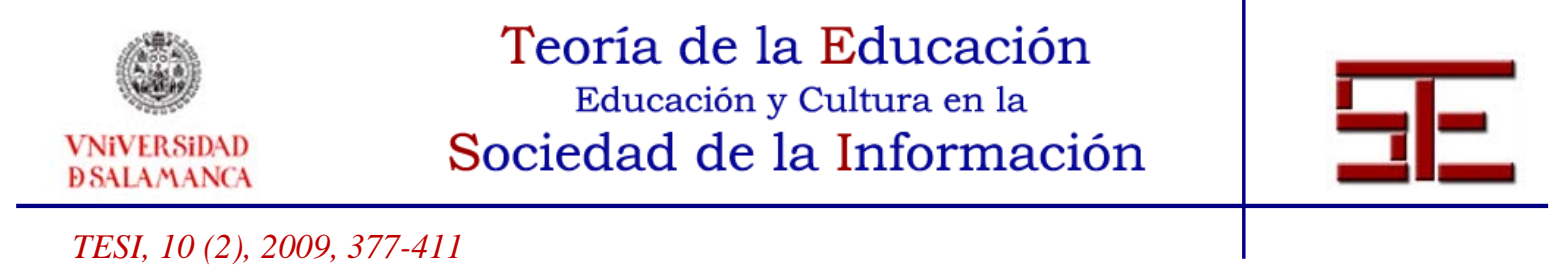

comunicación interpersonal entre hablantes de diferentes países y culturas; y el talante participativo y trabajo en colaboración.

Las competencias telemáticas fomentan principalmente: la participación activa del alumno en los procesos de aprendizaje y la construcción del conocimiento, el pensamiento creativo y crítico, el desarrollo de procesos de comunicación intercultural y un aprendizaje flexible y autónomo y permite que los alumnos comprendan asuntos culturales y sociales relacionados con la tecnología. Por eso, la adquisición de lenguas tiene que implicar la adquisición de competencias telemáticas que promueven principalmente la participación activa de los egresados en su proceso de aprendizaje y en el andamiaje del conocimiento, el desarrollo del pensamiento creativo y crítico y el proceso de comunicación intercultural y el aprendizaje flexible que les permite entender temas sociales relacionados con la tecnología.

\subsection{El estudio}

Nuestro tema de investigación surge a partir de la pregunta: ¿desarrolla realmente el programa de movilidad Erasmus tanto las competencias comunicativas y el uso de las TIC de los estudiantes que participan? La gran influencia del fenómeno de la multiculturalidad y del multilingüismo en la sociedad global y en el marco del Espacio Europeo de Educación Superior.

Se consideró de interés científico realizar un trabajo de campo centrado en el análisis de las competencias comunicativas y en el uso de las TIC de los estudiantes que participaron en el programa de intercambio Erasmus, con el objetivo de comprobar si el programa favorecía la adquisición de competencias comunicativas y también telemáticas. También se analizó desde una perspectiva teórica el nuevo escenario educativo de la educación superior, el papel de sus instituciones, del profesorado y de los alumnos.

La observación de los indicios nos llevó al planteamiento de la hipótesis que la estancia en otro país es un escenario óptimo que permite:

A) En cuanto a las competencias comunicativas: 1) la mejora de todas las competencias;

2) la interacción en un contexto real mejora la espontaneidad, flexibilidad y la fluidez;

3) la aplicación de conocimientos lingüísticos y habilidades comunicativas adquiridos en el aula, sobre todo, los relativos a la expresión y comprensión oral y escrita; 4) el ejercicio oral de expresión y comprensión de manera constante es de gran importancia,

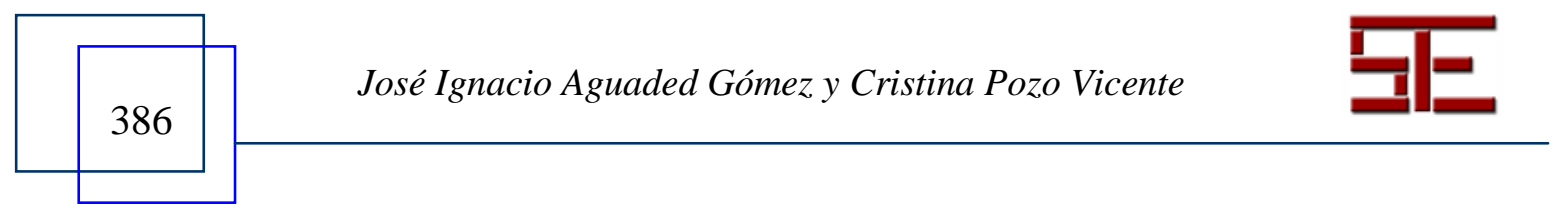




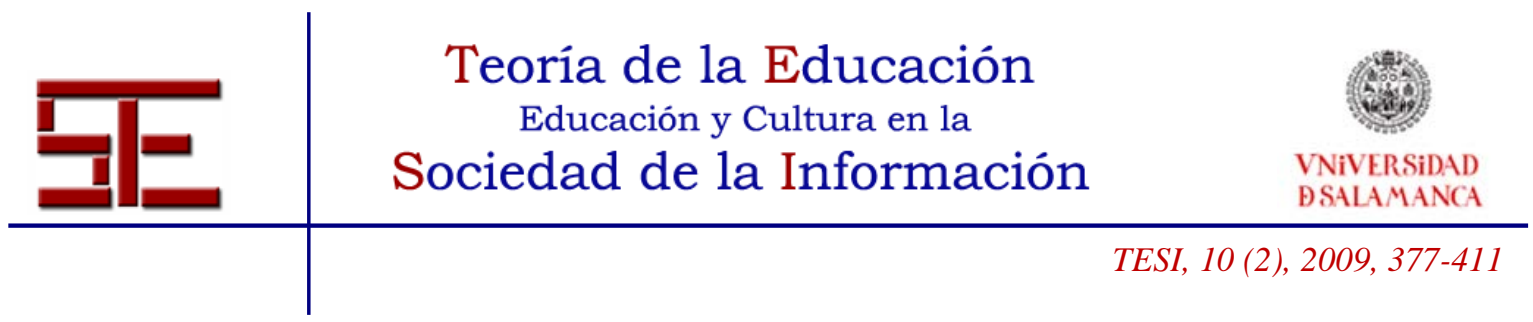

teniendo en cuenta que el fenómeno comunicativo es básicamente oral; 5) la ampliación del léxico, generalmente, de registro estándar-coloquial; 6) el contacto y el uso de otras lenguas; 7) la construcción de esquemas mentales basados en el plurilingüismo, es decir, «aprender a pensar y a comunicarse en diferentes sistemas lingüísticos»; 8) la adquisición de valores pluriculturales; 9) el aumento del uso de lenguas extranjeras mediante las TIC.

B) En cuanto a las competencias telemáticas: 1) la concienciación sobre el alcance de la red como fuente de información y comunicación actualizada, por ejemplo, la consulta y lectura de diarios nacionales; 2) la adquisición de conocimientos básicos y avanzados sobre el uso de la red; 3) el aumento generalizado del uso de internet y la navegación en la web; 4) el incremento considerable de herramientas de comunicación como el correo electrónico, los webblogs personales, las redes sociales (Facebook, StudiVz, etc.) y la mensajería instantánea; 5) el uso de internet como herramienta de comunicación y de búsqueda de información que no sean la lengua materna; 6) el desarrollo de competencias relacionadas con aspectos de la red.

\section{METODOLOGÍA}

\subsection{Metodología y proceso de la investigación}

Nuestro estudio no provoca ni manipula la variable independiente para ver qué efectos produce en la variable dependiente (Buendía y otros, 1998: 62), sino que se plantea la validación de hipótesis cuando el fenómeno ya ha sucedido, de forma retrospectiva. Las fases de nuestro trabajo de investigación, se caracterizan por la superposición en el tiempo. La fase preparatoria exigió la búsqueda y la revisión exhaustiva de literatura para documentar y fundamentar la teoría y el estudio empírico. Después, se procedió a concretar el diseño de la investigación definiendo muestra, población ( ${ }^{\circ}$ de estudiantes y centro), método y técnicas a utilizar en el análisis de las competencias telemáticas y comunicativas por parte del centro. En el diseño de la investigación se concretó que el cuestionario sería el instrumento básico, ya que es una herramienta representativa para contrastar puntos de vista en nuestro estudio. El análisis de los cuestionarios se concretó en un grupo de referencia. También se desarrolló la fase de negociación de acceso al campo.

El segundo periodo de la investigación consistió en la realización de dos cuestionarios completos con indicadores referentes a las competencias comunicativas de los

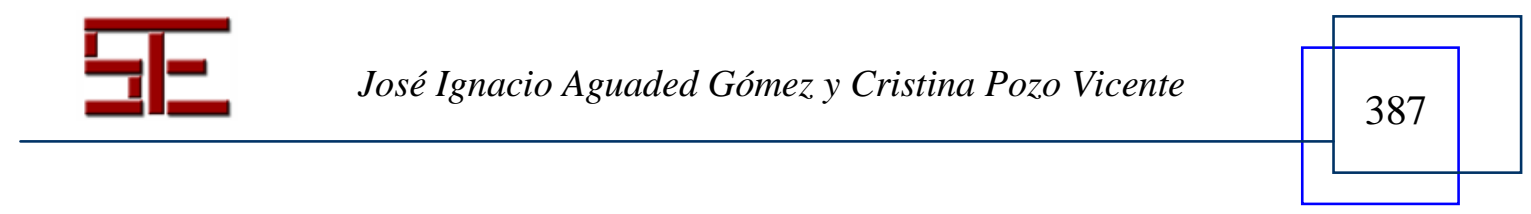




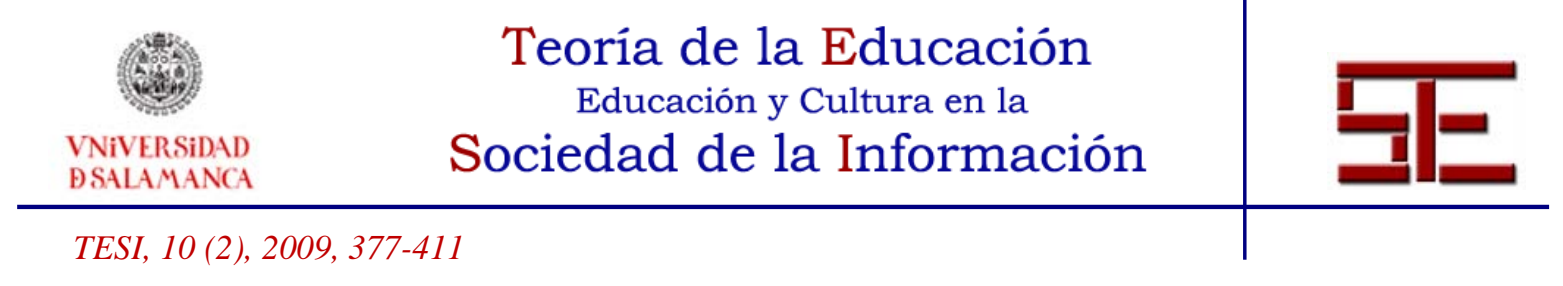

estudiantes y al uso de las TIC. El resultado del trabajo de campo fue una página web con domino propio www.cuestionarioserasmus.com. Esos cuestionarios se tradujeron a lenguaje HTML y a PHP para que, en primer lugar, los datos introducidos se almacenaran y se pudieran enviar en forma de correo electrónico y para facilitar el acceso y la introducción de los datos. En el procesamiento de los datos, se emplearon herramientas estadísticas como la media, la varianza (o la desviación media) y la desviación típica - parámetro de dispersión más utilizado y que se define como la raíz cuadrada positiva de la varianza-, lo que nos da un alto nivel de confianza y de margen de error del estudio y que nos ayuda a acercarnos a los datos correspondientes a la realidad. A posteriori, se llevó a cabo el análisis de los datos de los cuestionarios: tratamiento y análisis estadístico, a partir de los cuales se obtuvieron los resultados en los que se basan las conclusiones de esta investigación.

El resultado final de las tres fases principales de la investigación son: un fundamento teórico claro y coherente que define los tres ejes o bloques principales del trabajo como son la universidad del siglo XXI, las competencias comunicativas y las competencias telemáticas; y un estudio de campo representativo con cierta validez interna y externa.

\subsection{Muestra}

Los participantes constituyen el eje central del estudio, ya que aportan información esencial sobre una realidad y un fenómeno educativo de gran magnitud en Europa: el programa Erasmus. El objeto de estudio es el análisis de las competencias comunicativas y el uso de las TIC desarrolladas por los estudiantes Erasmus durante su periodo de estudios en España. Por eso, la muestra está formada principalmente por el grupopoblación de estudiantes Erasmus. Los informantes o sujetos de la investigación son: estudiantes de Hispánicas que han permanecido durante un periodo de tiempo en España gracias a una beca Erasmus. La selección de la población y la muestra se caracterizó por ser un muestreo intencional que requiere criterios fundamentados en la selección de la muestra. Esta estrategia se suele utilizar en diseños de estudio de caso único, como es el nuestro, es decir, en el que la recogida de información procede básica y exclusivamente de un informante clave -el grupo de estudiantes Erasmus del Romanisches Seminar de la Universität Bonn-. El requisito básico para participar en nuestra investigación era que los informantes fueran estudiantes de español que hubieran llevado a cabo sus estudios de Hispánicas en una universidad española durante un semestre o la totalidad del curso académico 2007/08. La muestra ascendió a un grupo de veinte estudiantes.

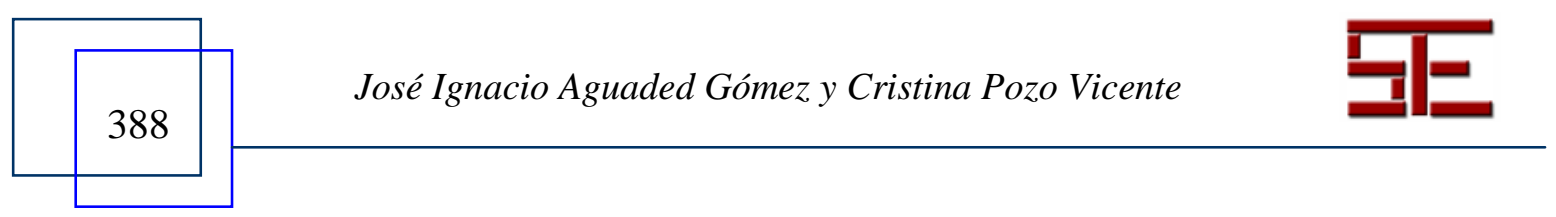




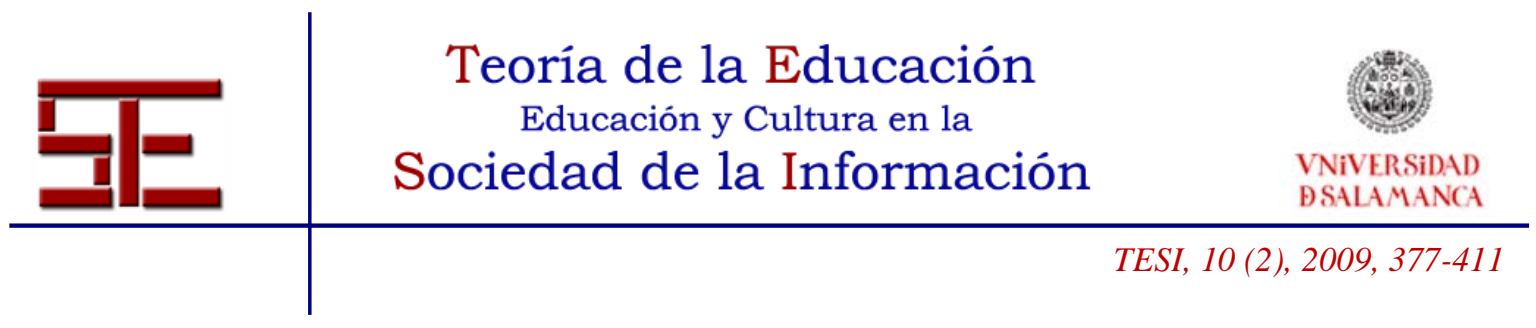

\subsection{Instrumentación}

El cuestionario se diseñó de forma metódica con preguntas que se correspondían a las variables seleccionadas, evitando las preguntas que no respondían al propósito de «medir» alguna variable de diagnóstico y el diseño de cuestionarios demasiado largos y mecánicos que hicieran que el encuestado perdiera interés. Las preguntas se agruparon en función del formato, lo que facilitó el procesamiento y el análisis de los datos.

La selección de las preguntas dependía de factores relacionados con la naturaleza de la información que se pretendía obtener: el nivel sociocultural y lingüístico de los encuestados, las características de los mismos y de los objetivos de la investigación. Seguimos las orientaciones de Rodríguez y otros (1996) para formular preguntas: a) relacionadas con el problema estudiado; b) no dadas a conocer por otros medios; c) teniendo en cuenta el modo de codificación o tabulación de las respuestas; d) que permitieran establecer comparaciones con otros estudios realizados sobre el mismo tema; e) de baja dificultad para los encuestados; y f) que no sean confidenciales.

El formato final de los dos cuestionarios resultó ser un conjunto de preguntas o cuestiones relevantes para el rasgo, característica o variable objeto de estudio y que se utilizan para la recogida de datos y orientadas a la medición y diagnóstico psicopedagógico. El diseño del cuestionario que es el eje central de nuestra investigación tiene un enfoque socioconstructivista y se configuró como una autoevaluación del propio aprendizaje, lo que permite al estudiante un análisis y una reflexión sobre sus conocimientos, en este caso, referentes a la lengua extranjera y a las TIC, y pretende el progreso y el desarrollo de esas competencias en el transcurso del tiempo.

Las preguntas que incluyen nuestros cuestionarios se clasifican en: abiertas, cerradas y de elección múltiple (con respuesta en abanico o de estimación). Las preguntas abiertas tienen como finalidad no dar límite a la respuesta y darles la opción de expresarse en su propio lenguaje. También se han incluido afirmaciones en clave de pregunta con las que se pretende obtener respuestas confirmatorias o desestimativas; es el caso del bloque de autoevaluación, en el que el estudiante tiene que afirmar o desestimar diversas competencias referentes a las cinco actividades comunicativas principales: comprensión auditiva, comprensión escrita, expresión oral, expresión escrita e interacción oral.

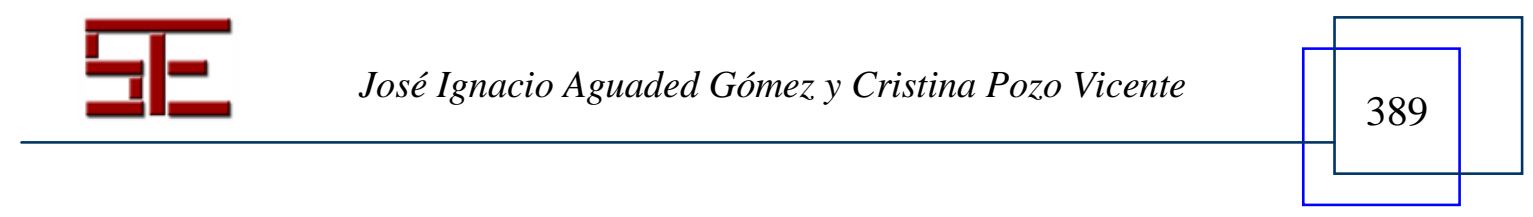




\section{CUESTIONARIO SOBRE LAS COMPETENCIAS COMUNICATIVAS EN LA LENGUA EXTRANJERA}

Introduzca su dirección de correo electrónico:

1.) Ha sido estudiante ERASMUS? $\bigcirc$ sí $\bigcirc$ No

2a.) (Si, he sido estudiante ERASMUS) Indique el número de lenguas en las que estuvo en contacto durante ese periodo: de estudio $0 \mathrm{~V}$

¿Cuáles?

3a.) (Sí, he sido estudiante ERA SMUS) Indique qué lenguas ha aprendido o comenzó a aprender durante ese periodo

2b.) (No, no he sido estudiante ERASMUS) Indique el número de lenguas que está en contacto en estos momentos: $0 \mathrm{v}$

¿Cuáles?

3b.) (No, no he sido estudiante ERASMUS) Indique qué lenguas está aprendiendo o ha comenzado a aprender

4.) Motivos del aprendizaje del español:

$\bigcirc$ profesional $\bigcirc$ personal $\bigcirc$ académico $\bigcirc$ Otro ¿Cuál?

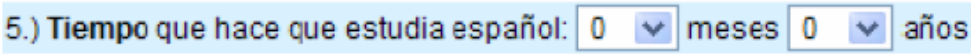

6.) Ámbito de uso de la lengua española:

$\bigcirc$ profesional $\bigcirc$ personal $\bigcirc$ académico $\bigcirc$ Otros ¿Cuál?

Ejemplo 1 del bloque de autoevaluación (cuestionario de competencias comunicativas)

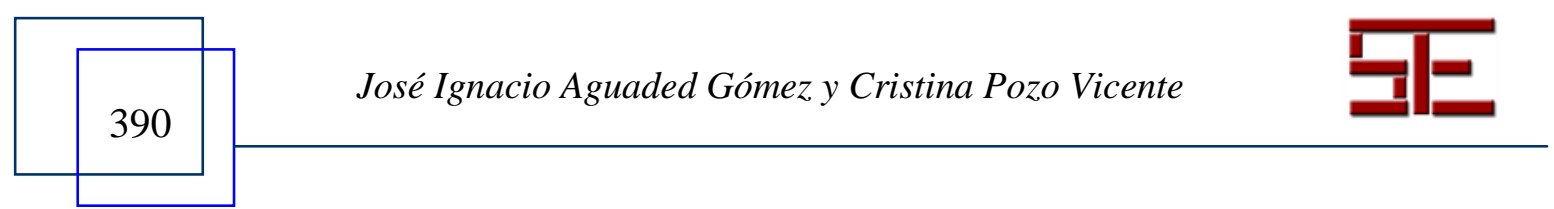




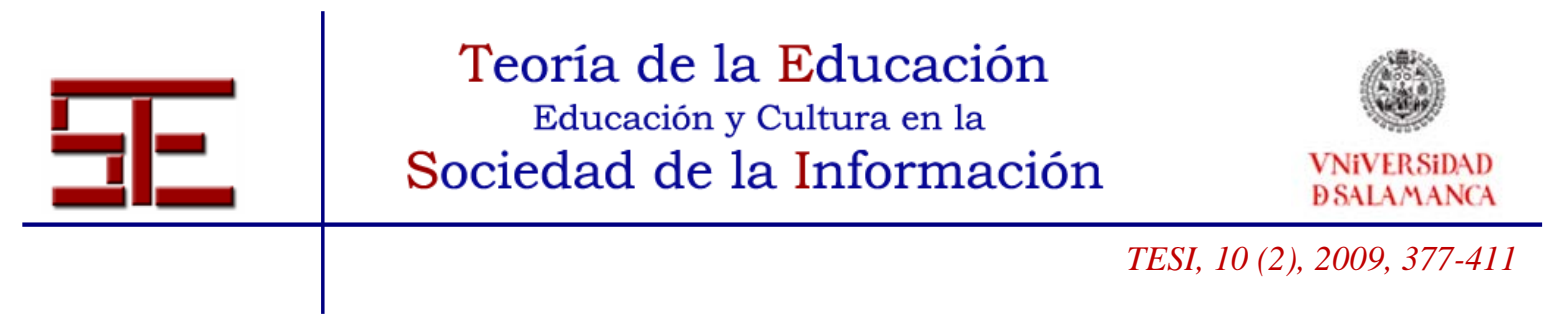

Marque en antes Y/o después las actlvidades que usted cree que actualmente es capaz de realizar en español y al lado marque las actividades que usted cree que era capaz de realizar antes del Erasmus en esa lenoua. En caso de que sea capaz antes y después del Erasmus marque con una cruz las dos casillas. Recuerde también que pueden ser más de una competencia.

\begin{tabular}{|l|c|c|}
\hline 7.) Comprensión auditiva & Antes & Ahora \\
\hline $\begin{array}{l}\text { 7.1) No tengo ninguna dificultad para entender cualquier tipo de texto de la lengua hablada en } \\
\text { todas las situaciones y contextos }\end{array}$ & $\square$ \\
\hline $\begin{array}{l}\text { 7.2) Al escuchar, reconozco palabras y expresiones básicas y habituales si se habla } \\
\text { despacio }\end{array}$ & $\square$ & $\square$ \\
\hline $\begin{array}{l}\text { 7.3) Comprendo a nivel de lengua hablada textos y discursos claros sobre temas de lavida } \\
\text { cotidiana y entiendo la idea principal de programas de radio o televisión }\end{array}$ & $\square$ & $\square$ \\
\hline $\begin{array}{l}\text { 7.4) En una conversación oral, entiendo frases y vocabulario más habitual sobre temas de } \\
\text { interés personal y capto la idea principal de avisos y mensajes breves }\end{array}$ & $\square$ & $\square$ \\
\hline \begin{tabular}{l} 
7.5) Comprendo casi sin esforzarme todo tipo de textos y discursos de la lengua oral \\
\hline $\begin{array}{l}\text { 7.6) Entiendo a nivel de lengua hablada todo tipo de noticias y discursos extensos sobre } \\
\text { temas de actualidad }\end{array}$
\end{tabular} & $\square$ & $\square$ \\
\hline
\end{tabular}

\begin{tabular}{|l|c|c|}
\hline 8.) Comprensión lectora & Antes & Ahora \\
\hline 8.1) Comprendo al leer palabras y frases simples & $\square$ & $\square$ \\
\hline $\begin{array}{l}\text { 8.2) Puedo leer fácilmente y sin problemas todo tipo de lengua escrita, incluyendo textos } \\
\text { abstractos estructural o lingǘsticamente complejos }\end{array}$ & $\square$ & $\square$ \\
\hline $\begin{array}{l}\text { 8.3) Entiendo textos largos y complejos de carácter literario y artículos especializados e } \\
\text { instrucciones técnicas }\end{array}$ & $\square$ \\
\hline \begin{tabular}{l} 
8.4) Puedo leer arlículos e informes de opinión y también entiendo la prosa lieraria fácil \\
\hline $\begin{array}{l}\text { 8.5) Entiendo al leer textos escritos en la lengua de uso habitual y cotidiano y entiendo la } \\
\text { cescripción de acontedmientos, sentımientos y deseos en cartas personales }\end{array}$
\end{tabular} & $\square$ & $\square$ \\
\hline $\begin{array}{l}\text { 8.6) Comprendo textos breves y sencillos y encontrar información especifica en, por ejemplo, } \\
\text { menús y horarios }\end{array}$ & $\square$ & $\square$ \\
\hline
\end{tabular}

Ejemplo 2 del bloque de autoevaluación (cuestionario de competencias telemáticas)

\section{CUESTIONARIO SOBRE LAS COMPETENCIAS TELEMÁTICAS}

Introduzca su dirección de correo electrónico:

Indique con la escala del 5 (mayor trecuencia) al 1 (no usuario) el uso, las lenouas y los objetivos de la utilización de los recursos tecnolódicos. Para no tener que pinchar cada vez encima del recuadro con el ratón, puede usar el tabulador y los números de su teclado. De esa manera, se agiliza el proceso de intraducciön de los datos en el cuestionario. (Statt mit der Maus können die Antworten auch mit der Hilfe der Tabulatortaste und den Nummerntasten eingetragen werden. was die Eingabe erleichtert).

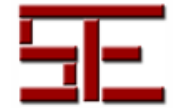

José Ignacio Aguaded Gómez y Cristina Pozo Vicente 


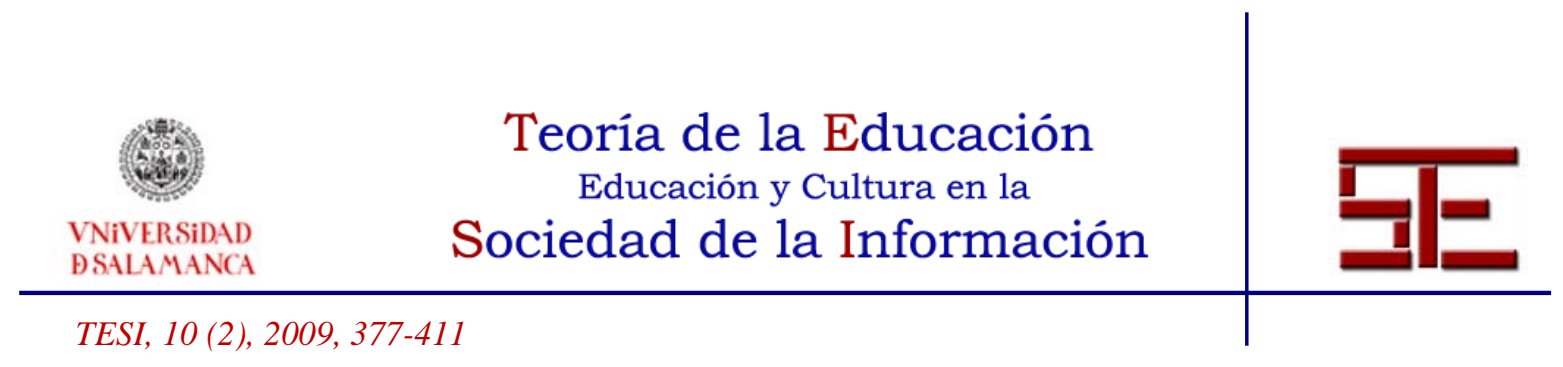

\begin{tabular}{|c|c|c|c|c|c|c|}
\hline \multirow[b]{2}{*}{ Uso de Internet } & \multicolumn{2}{|l|}{$\begin{array}{l}\text { Antes del } \\
\text { Erasmus }\end{array}$} & \multicolumn{2}{|l|}{$\begin{array}{l}\text { Durante el } \\
\text { Erasmus }\end{array}$} & \multicolumn{2}{|c|}{$\begin{array}{l}\text { Ahora / después } \\
\text { del Erasmus }\end{array}$} \\
\hline & & & & & & \\
\hline Navegación en la web & 1 & $\checkmark$ & 1 & $\checkmark$ & 1 & $\checkmark$ \\
\hline \multicolumn{7}{|l|}{ Objetivos de uso de internet } \\
\hline Consulta de páginas webs & 1 & $\checkmark$ & 1 & $\checkmark$ & 1 & $\checkmark$ \\
\hline Utilización de correo electrónico & 1 & $\checkmark$ & 1 & $\checkmark$ & 1 & $\checkmark$ \\
\hline Utilización de buscadores & 1 & $\checkmark$ & 1 & $\checkmark$ & 1 & $\checkmark$ \\
\hline $\begin{array}{l}\text { Consulta de enciclopedias o diccionarios } \\
\text { online }\end{array}$ & 1 & $\checkmark$ & 1 & $\checkmark$ & 1 & $\checkmark$ \\
\hline $\begin{array}{l}\text { Descarga de ficheros (música, programas, } \\
\text { etc.) }\end{array}$ & 1 & $\checkmark$ & 1 & $\checkmark$ & 1 & $\checkmark$ \\
\hline Mantenimiento y creación de webblog personal & 1 & $\checkmark$ & 1 & $\checkmark$ & 1 & $\checkmark$ \\
\hline Participación en chats de webblogs & 1 & $\checkmark$ & 1 & $\checkmark$ & 1 & $\checkmark$ \\
\hline Reproducción de videos & 1 & $\checkmark$ & 1 & $\checkmark$ & 1 & $\checkmark$ \\
\hline Videojuegos online & 1 & $\checkmark$ & 1 & $\checkmark$ & 1 & $\checkmark$ \\
\hline Participación en webforums & 1 & $\checkmark$ & 1 & $\checkmark$ & 1 & $\checkmark$ \\
\hline Creación de una pagina de web & 1 & $\checkmark$ & 1 & $\checkmark$ & 1 & $\checkmark$ \\
\hline
\end{tabular}

Tras el diseño y la elaboración del cuestionario se llevó a cabo un proceso de validación consistente en la realización de una prueba piloto en la que, se añadieron unas preguntas para la valoración global del cuestionario. Dicha prueba piloto también sirvió para que se corrigieran las deficiencias detectadas y se realizaran los cambios pertinentes. Posteriormente, se envió el enlace de los cuestionarios a los estudiantes que se habían mostrado interesados en participar en la investigación. Se creó la página web como soporte para realizar las encuestas con el objetivo de aprovechar las posibilidades que ofrecen las aplicaciones de las TIC y para promocionar su uso en el ámbito académico.

En la recepción de los cuestionarios completados por los estudiantes se generaba automáticamente un correo electrónico, copia de los datos introducidos en los cuestionarios, que iba dirigido al buzón de correo de la investigadora.

En el proceso analítico de la información obtenida a partir de los cuestionarios se siguieron las recomendaciones de Rodríguez y otros (1996: 237) «las posibilidades del ordenador en el almacenamiento, manejo y transferencia de grandes cantidades de información numérica, verbal o visual, y su rapidez en la realización de cómputos,

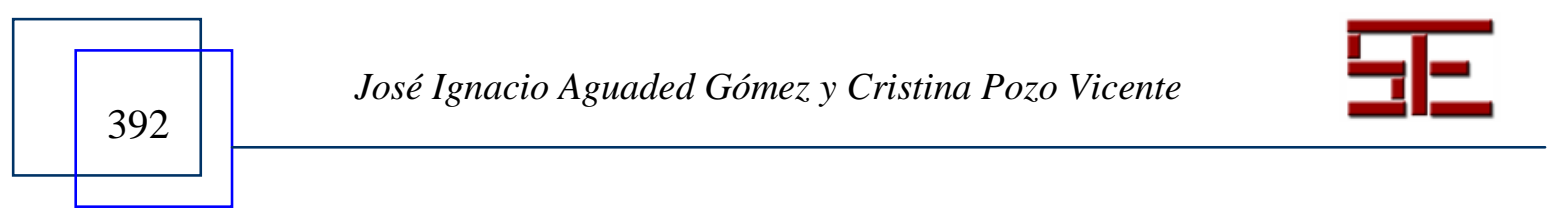




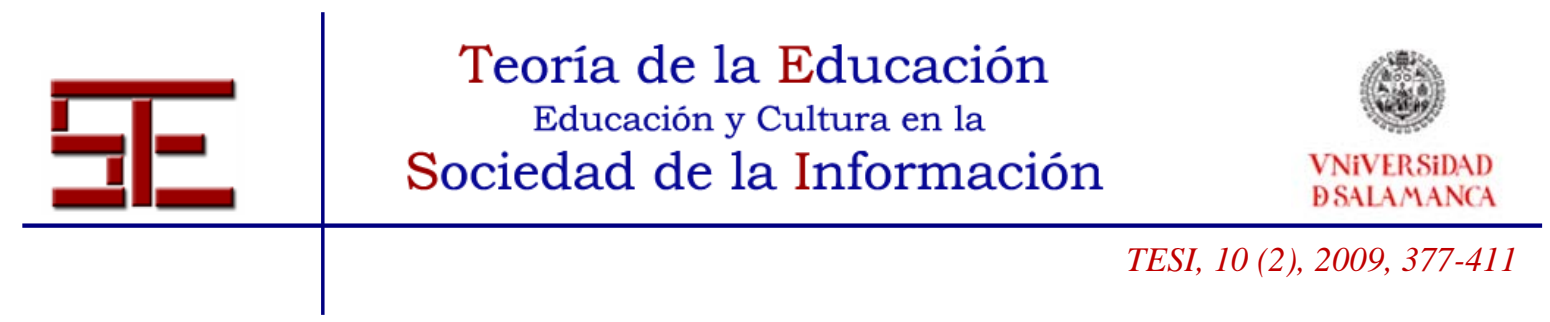

cálculos o tareas de búsqueda y organización, le han situado en un lugar privilegiado en un amplio abanico de campos científicos y profesionales». Se emplearon las herramientas de Microsoft Office Excel 2003 para el tratamiento de los datos.

Con la introducción de la matriz de los datos resultantes de los cuestionarios en la hoja de cálculo se puede identificar la información numérica y, a partir, de esa información se pueden procesar operaciones estadísticas. Los cálculos de la información se realizan a partir de fórmulas y funciones que son instrucciones. En nuestra investigación se ha trabajado con funciones tales como [=PROMEDIO (Rango)] (para el concepto de media), [=VARP (Rango)] (para el concepto de varianza) y [=DESVESTP (Rango)] (para el concepto de desviación típica).

\subsection{Análisis de los datos}

En el capítulo de la investigación que trata el análisis de los resultados se exponen los resultados estadísticos acompañados de un análisis cualitativo relativos a: 1) las competencias comunicativas y 2) el uso de las TIC.

En cuanto a las competencias comunicativas se presentan los módulos de: la media de niveles, el crecimiento puntual de los niveles de competencias, la desviación típica, la frecuencia en los diferentes periodos, de las lenguas en contacto y de diferentes competencias básicas de los actos comunicativos: la comprensión lectora, la comprensión oral, la expresión oral y escrita y la interacción oral.

Figura 1. Media de los niveles de competencias

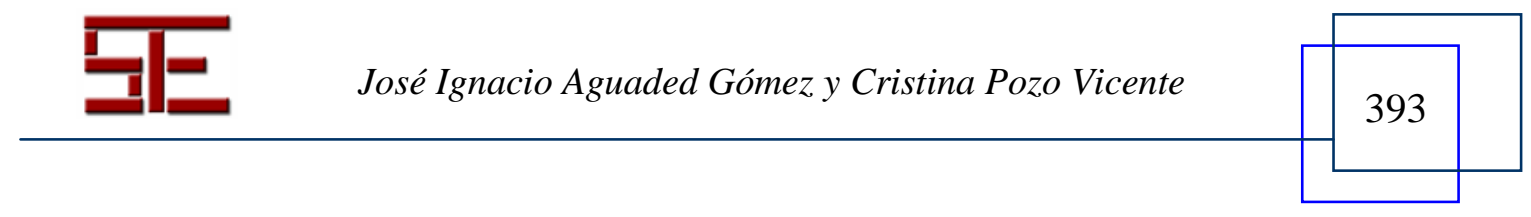



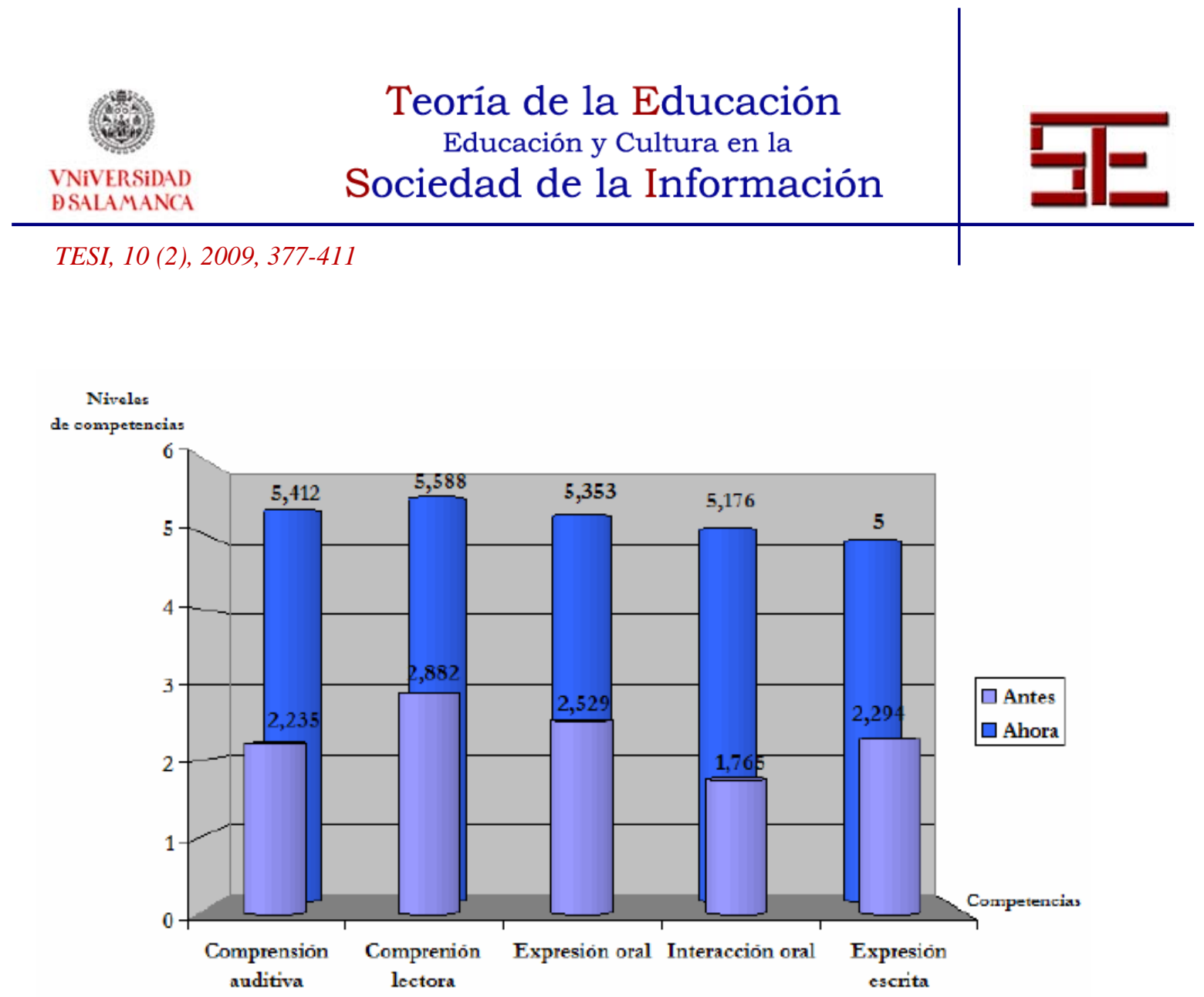

Fuente: elaboración propia

En la Figura 1 se representa la media de los niveles de competencias de Antes y Ahora. Cabe destacar que la competencia más desarrollada antes del Erasmus era la Comprensión lectora y la menos, la Interacción oral. Sin embargo, en la Figura 1 Ahora, se percibe un crecimiento general de las competencias comunicativas, en Ahora el nivel de competencia se sitúa entre los niveles C1 y C2. La Comprensión lectora, tras la estancia en el extranjero, es la competencia que presenta un nivel de desarrollo más elevado, pero cabe destacar que las actividades relacionadas con competencias de carácter oral son las han experimentado un mayor crecimiento: Comprensión auditiva, Expresión oral, Interacción oral. La competencia menos adquirida es la Expresión escrita.

Figura 2. Crecimiento puntual de las competencias

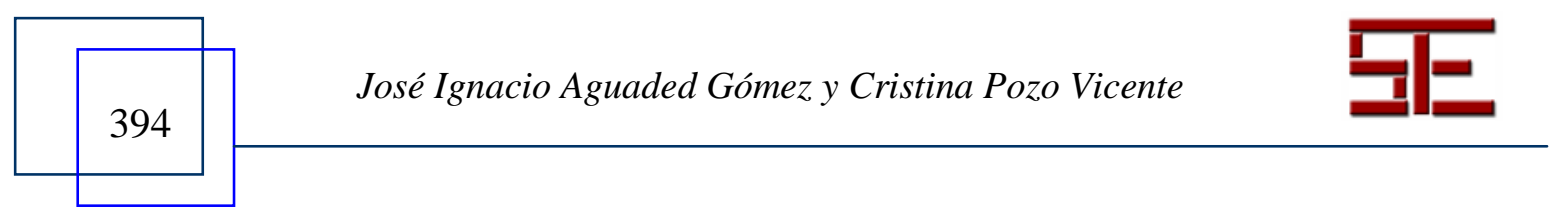



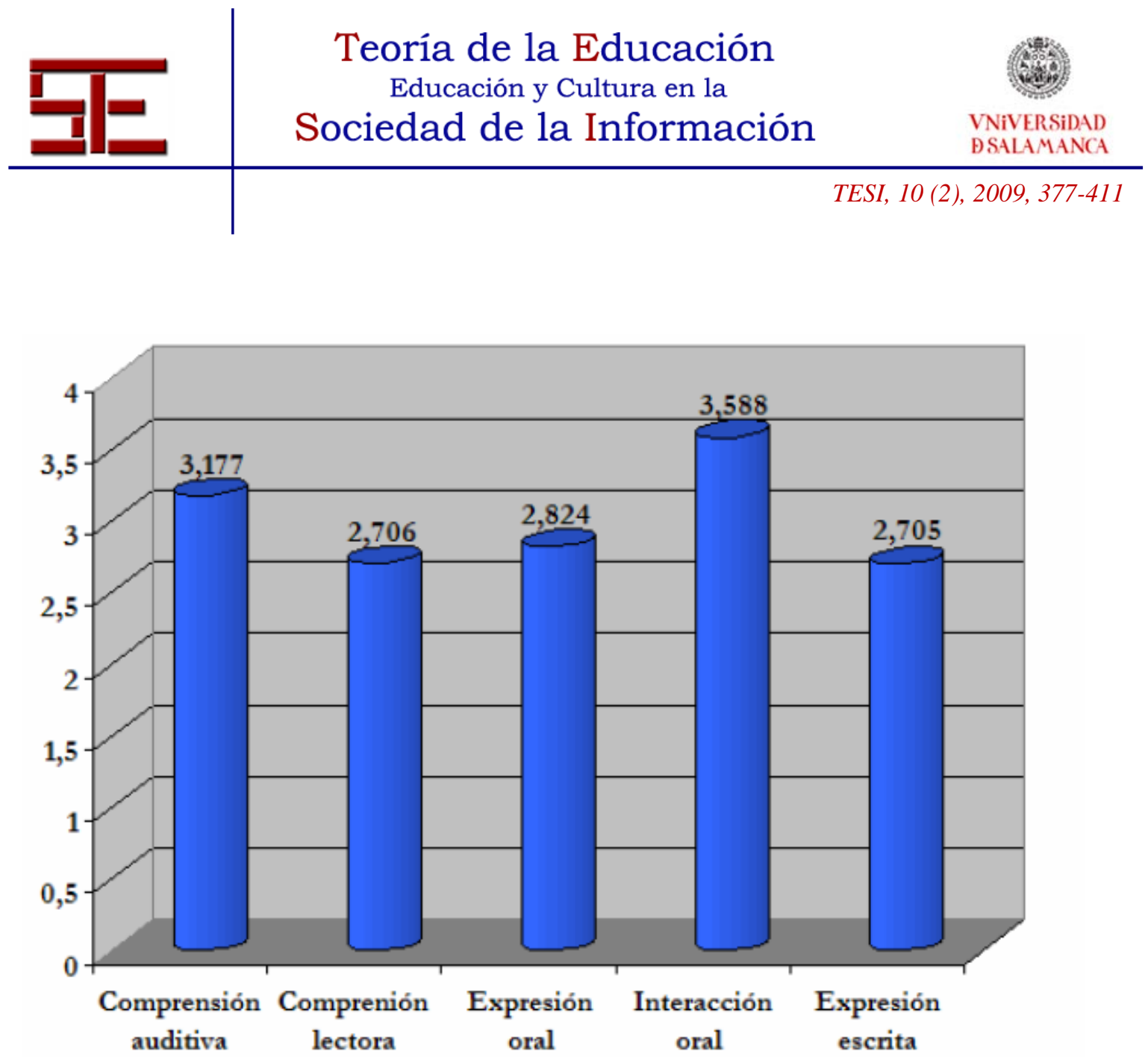

Fuente: elaboración propia

Fuente: elaboración propia

La diferencia entre las medias expresa la mejora general en cada una de las competencias de los informantes. La Figura 2 pretende demostrar el crecimiento en puntos de las competencias, resultante de la sustracción de Antes y Ahora de la Figura 1. En el gráfico se comprueba que el crecimiento presenta el siguiente orden (de mayor a menor): 1) Interacción oral, 2) Comprensión auditiva, 3) Expresión oral, 4) Comprensión lectora, y 5) Expresión escrita. Eso significa que las competencias relacionadas con actividades orales resultan ser las que han percibido un mayor crecimiento después del periodo Erasmus. Cabe destacar que la Interacción oral en el periodo Antes del Erasmus era la competencia menos desarrollada, mientras que en la Figura 2 se muestra como la actividad con un mayor crecimiento. En la Figura 1 la Expresión escrita era en Ahora la actividad menos desarrollada por los estudiantes

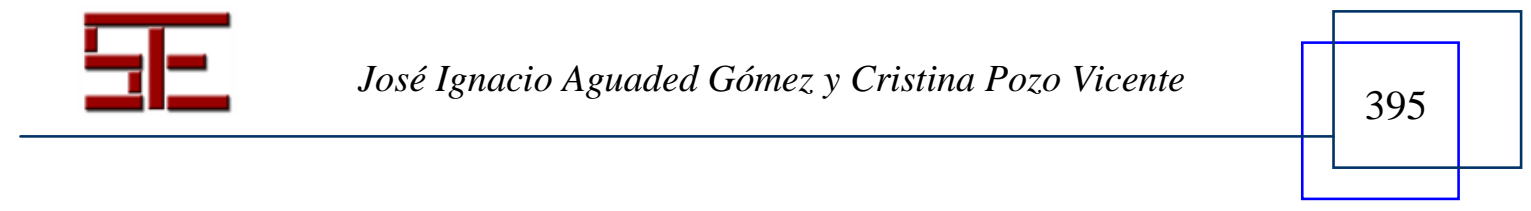




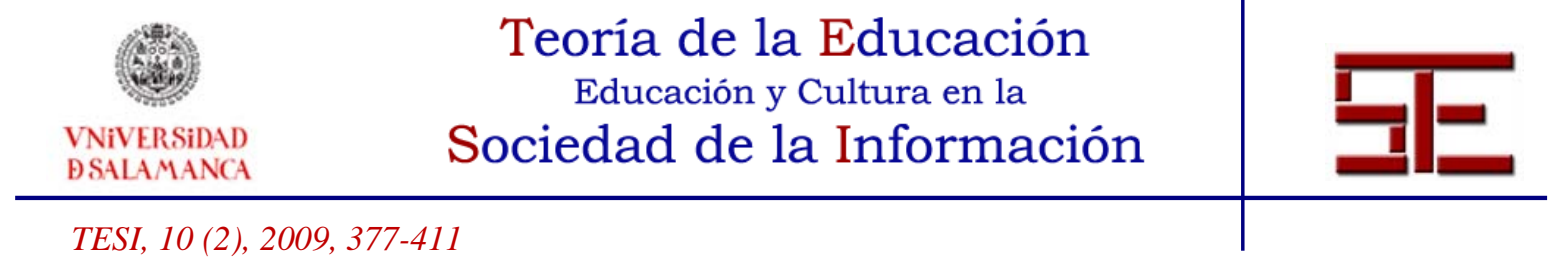

durante su periodo Erasmus y en la Figura 2, además, se muestra como la competencia que ha experimentado un menor crecimiento.

La desviación típica es la medida de dispersión más utilizada en la estadística descriptiva y ésta nos informa sobre la medida de las distancias que tienen los datos respecto a su media aritmética. En nuestra investigación, la desviación típica de los niveles de competencias pretende aportar información sobre la diferencia entre los niveles en competencias comunicativas de los informantes. Es decir, cuanto mayor sea la desviación típica, mayores serán las diferencias entre los niveles de los informantes y viceversa.

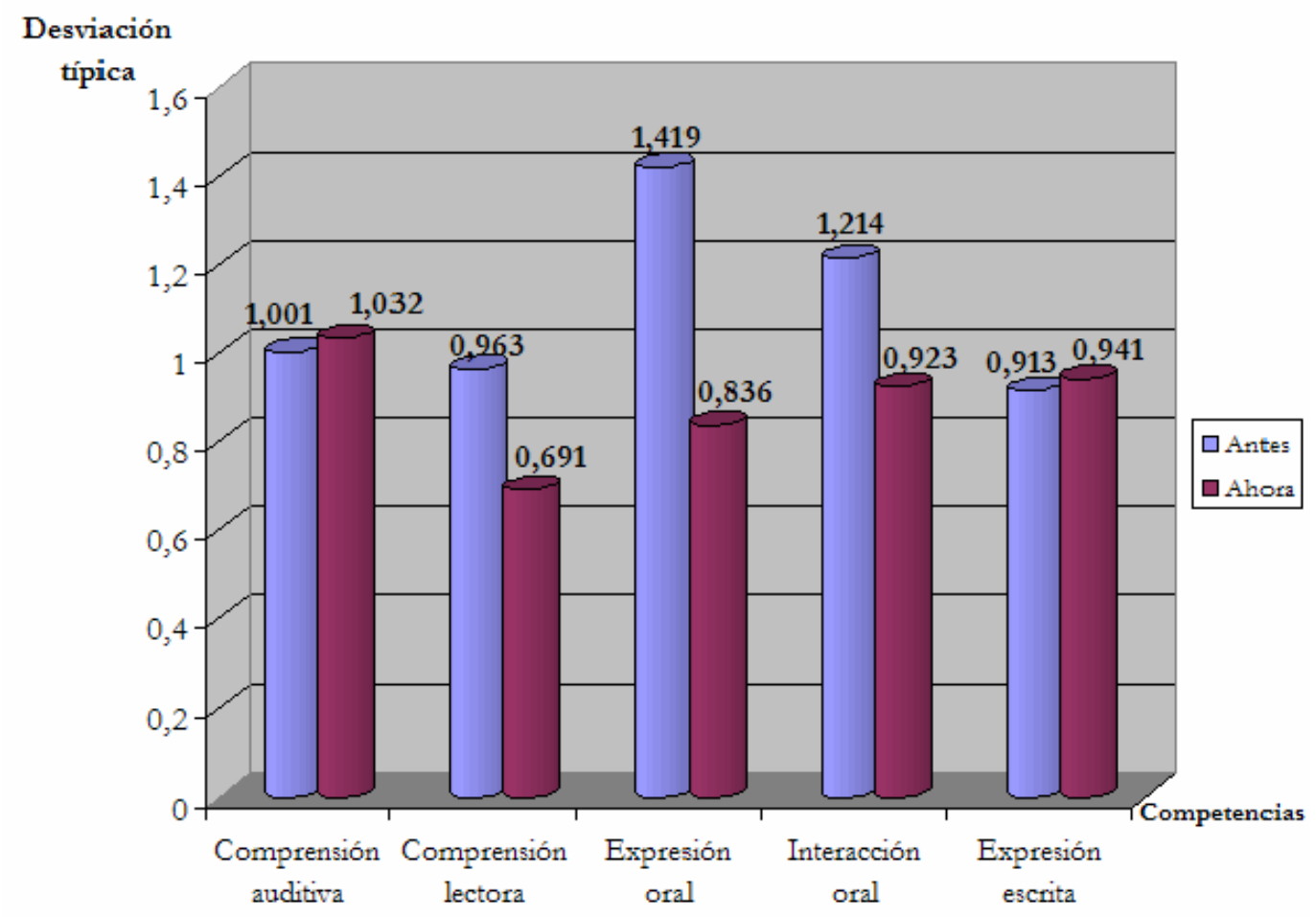

Fuente: elaboración propia

Como se puede comprobar en la Figura 3, existe una mayor desviación típica en las competencias Compresión lectora, Interacción oral y Expresión oral en Antes. Eso significa que los niveles de alumnos de esas competencias en el periodo anterior al Erasmus presentaban una mayor dispersión y, por lo tanto, los niveles entre los informantes se caracterizaban por una mayor desigualdad. Sin embargo, en el periodo

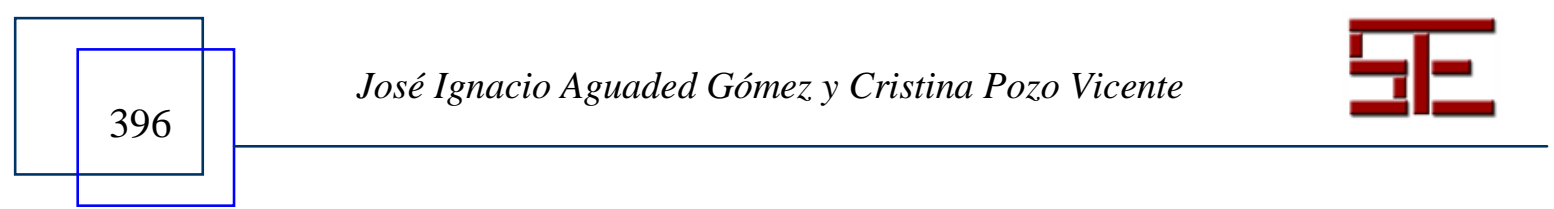




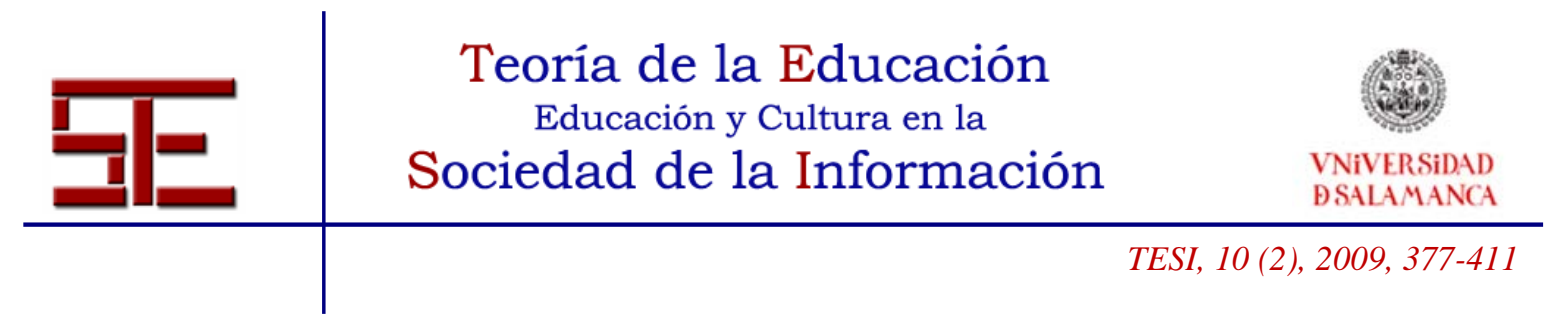

posterior a la estancia en el extranjero, esas tres competencias son las que muestran una menor dispersión de los datos, es decir, son las que han experimentado una mayor aproximación a la media. La Comprensión auditiva presenta prácticamente la misma dispersión en los dos periodos, al igual que la Expresión escrita.

Cabe destacar que los informantes procedían de diferentes cursos y habiendo estudiado español durante periodos disímiles. La media del tiempo de estudio del español de los informantes es de tres años y tres meses, pero en ese promedio cabe destacar que la varianza es enormemente elevada 1173,31 y la desviación típica también, 34,25. Esa también puede ser la razón que explique la gran dispersión y la diferencia entre los niveles en el periodo Antes del Erasmus. Sin embargo, los niveles después del Erasmus se igualaron, siendo una muestra de ello una desviación típica de las competencias considerablemente menor, en la mayoría de los casos. Eso nos sugiere pensar que la estancia en el extranjero se presenta como una oportunidad para desarrollar y adquirir un elevado nivel de competencia, independientemente del nivel anterior a la estancia, y en el que los niveles se mejoran y se equiparan.

Figura 4. Niveles de competencias „Antes”

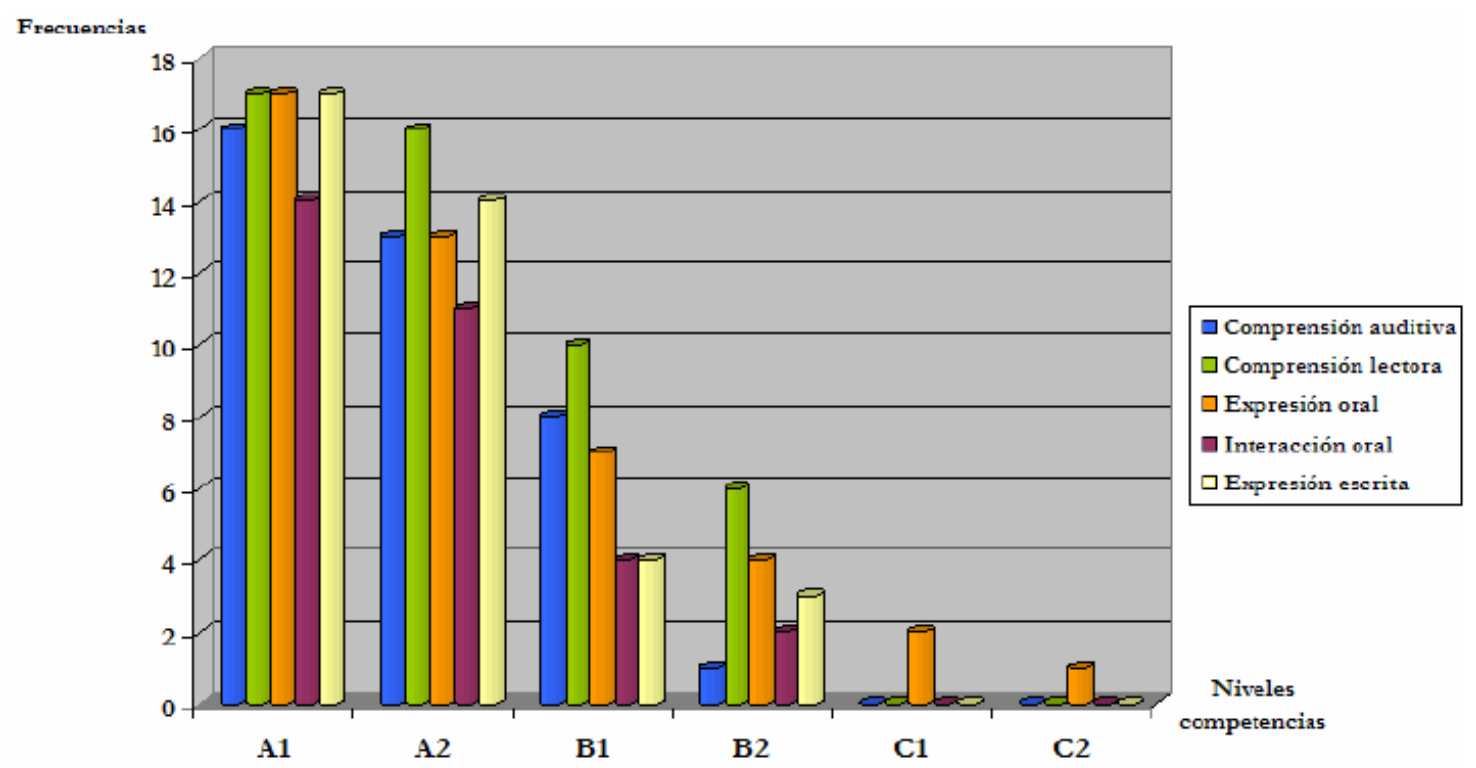

Fuente: elaboración propia

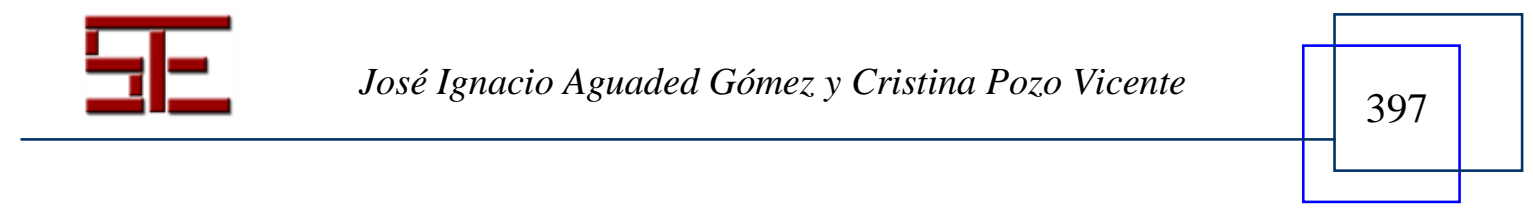




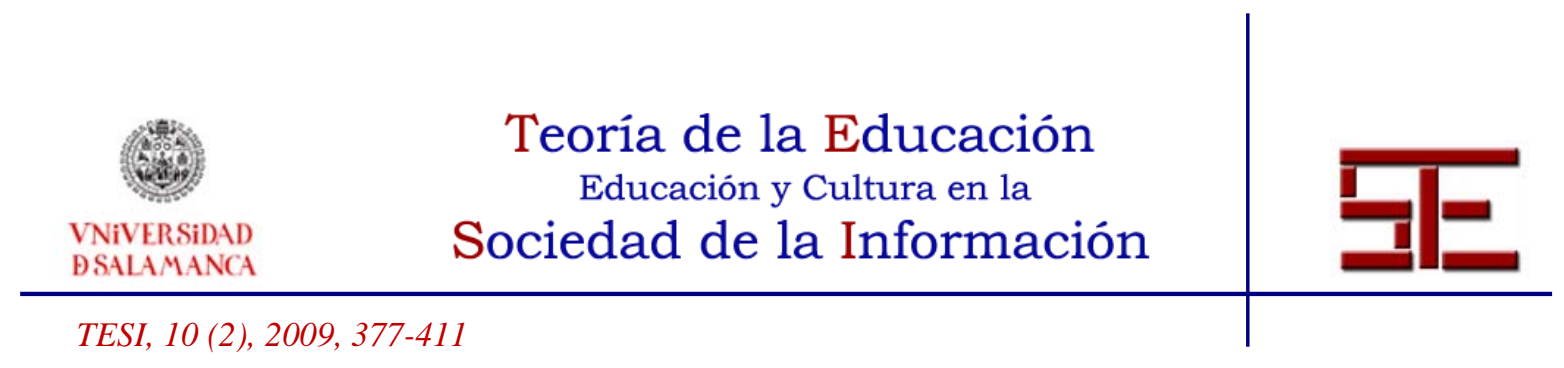

Figura 5. Niveles de competencias „Ahora”

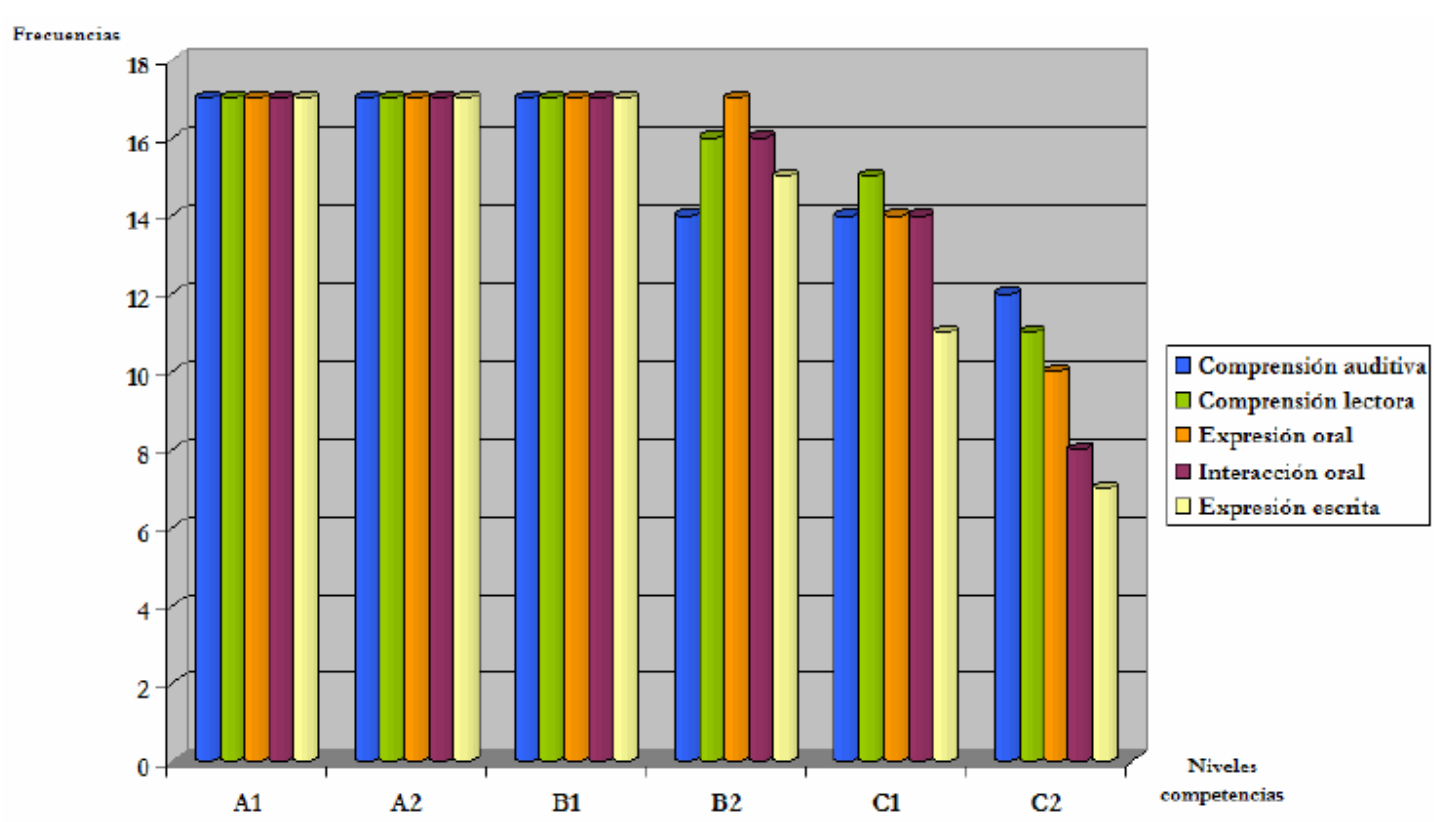

Fuente: elaboración propia

En la Figura 4 se muestra un gráfico con los niveles de competencias relacionadas con las competencias de los informantes en el periodo anterior a la estancia en el extranjero. En términos generales, en el gráfico se percibe una tendencia de los niveles claramente decreciente. La mayoría de las competencias de los estudiantes antes del periodo Erasmus se situaban en los niveles A1 y A2, siendo la comprensión lectora y la comprensión auditiva las menos desarrolladas. En el gráfico aparecen dos datos inesperados, en C1 y C2 en las que la expresión oral de dos informantes era la más desarrollada. Ese dato se debe a que esos estudiantes son hijos de padres españoles, por lo que en casa tiene lugar principalmente una comunicación oral.

En la Figura 5 se representan los niveles de competencias de los informantes en Ahora, periodo posterior a la estancia en el extranjero, relacionado con las competencias. El total de los informantes consideraron haber adquirido tras la estancia en España hasta el nivel B1 en todas las competencias, mientras que en periodo anterior al Erasmus no todos los estudiantes creían haber alcanzado el nivel mínimo, A1. En general, en la Figura 5 se comprueba que las competencias con un mayor desarrollo varían en función también del nivel de competencia.

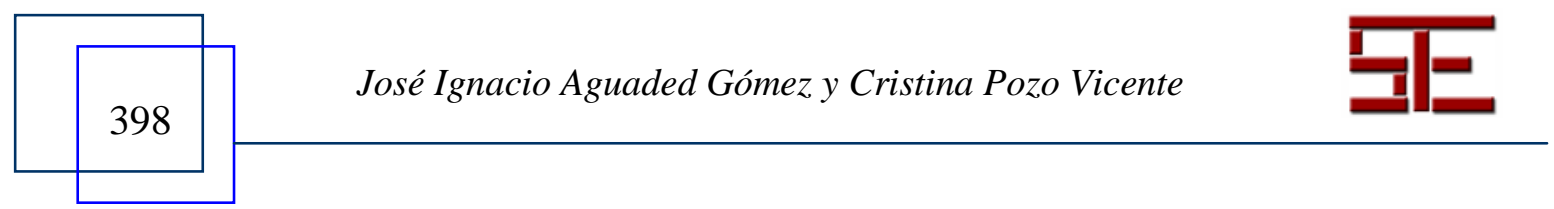




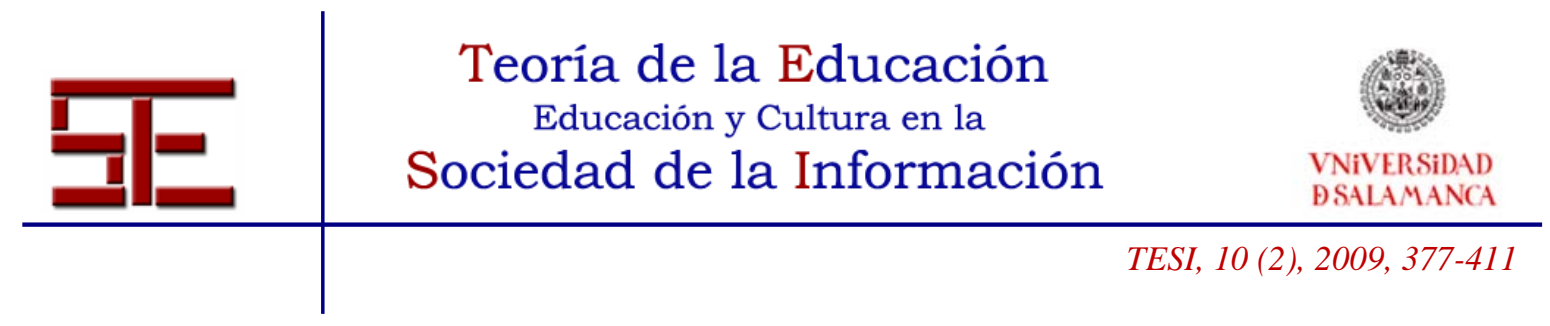

Figura 6. Lenguas en contacto durante la estancia en el extranjero Erasmus

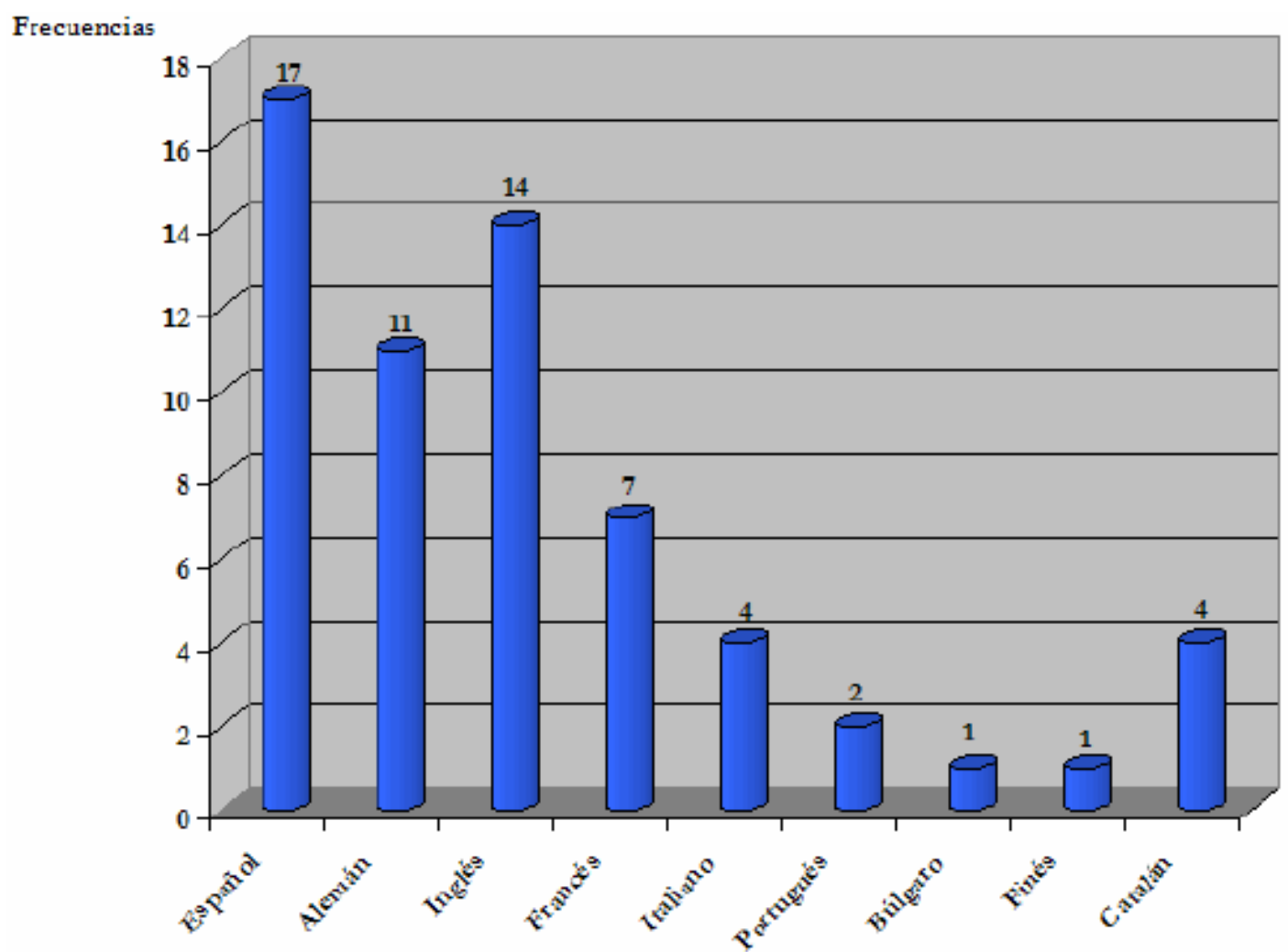

Fuente: elaboración propia

Durante la estancia en el extranjero, se entra en contacto con diferentes lenguas en función del país de recepción, del entorno de amistades, de la procedencia de los estudiantes. La totalidad de los informantes afirmaron haber entrado en contacto con un gran número de lenguas (véase Figura 6). El español es la lengua con un mayor número de casos, ya que se trata de la lengua oficial del país de recepción de los informantes durante su estancia en el extranjero. En cambio, el inglés se trata de la lengua internacional de comunicación entre las personas, de forma que cualquier persona que no pueda comunicarse en la lengua del país de recepción y que, además, no compartan la misma lengua materna, se verán forzados a usar el inglés como lengua vehicular y, de ahí, que también sea una lengua en contacto. El alemán también tiene importancia por ser la lengua materna o la lengua de procedencia de los informantes. Una persona puede

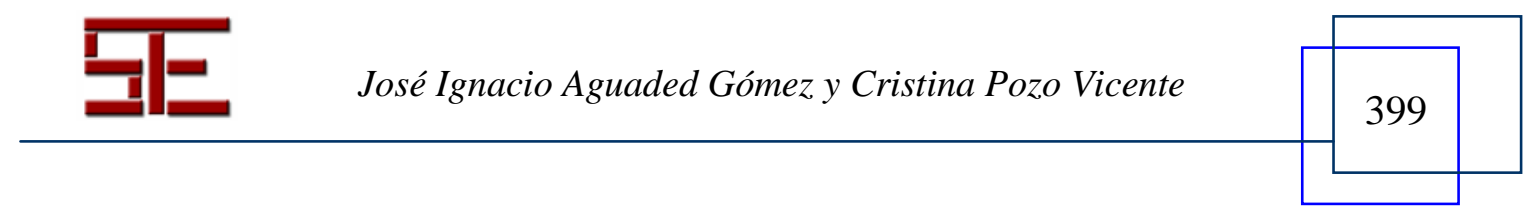




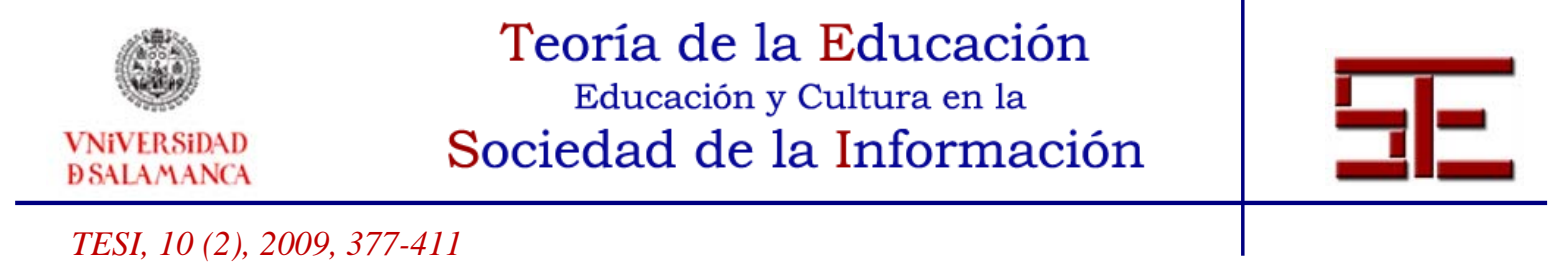

haber entrado en contacto con diferentes lenguas, es decir, en su entorno se hablan diversas lenguas, pero esa persona solo emplea una lengua vehicular para comunicarse con su entorno.

En el apartado de análisis del uso de las TIC se observaron principalmente los datos referentes a: la frecuencia de las actividades en la red relacionadas con la comunicación la búsqueda de información; de la lengua de búsqueda, de información y de comunicación en la red; y de las competencias relacionadas con los sistemas informáticos (hardware, redes, software), con el sistema operativo, con el uso de programa básicos y con el uso de internet, representadas a partir de gráficos.

Figura 7. Actividades en la red relacionadas con la comunicación y la búsqueda de información

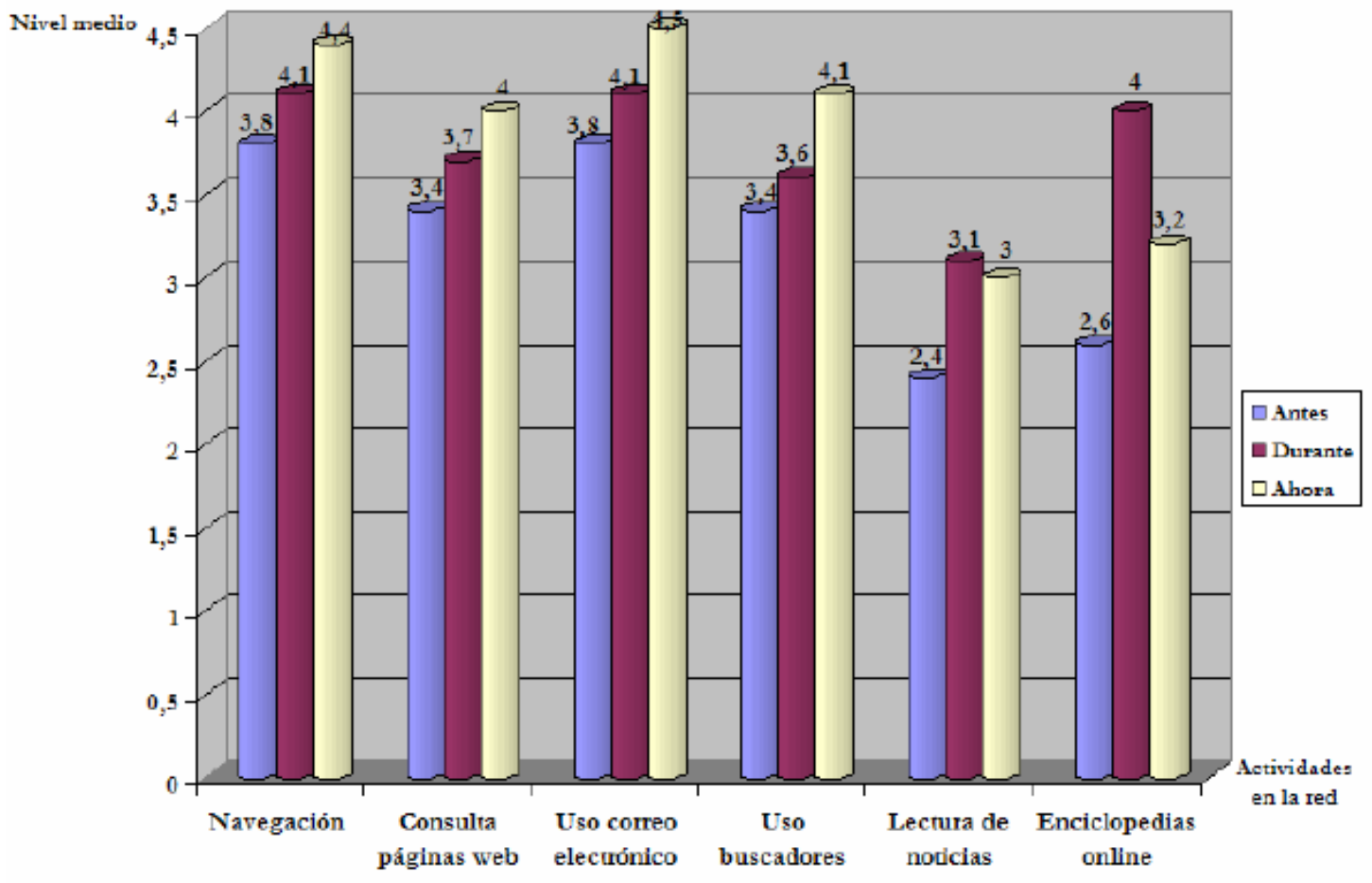

Fuente: elaboración propia

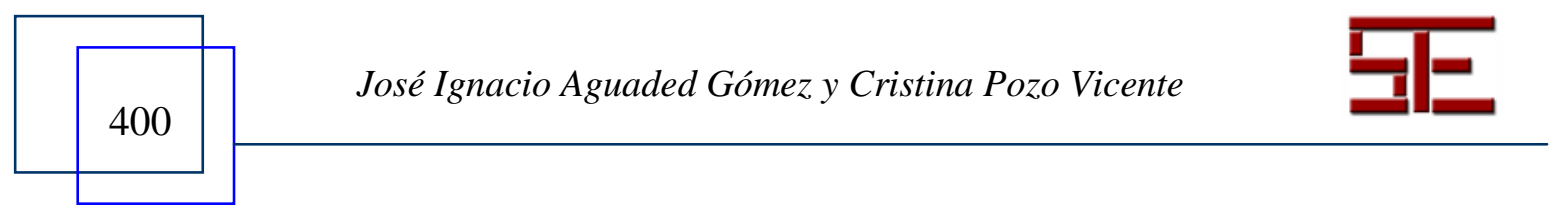




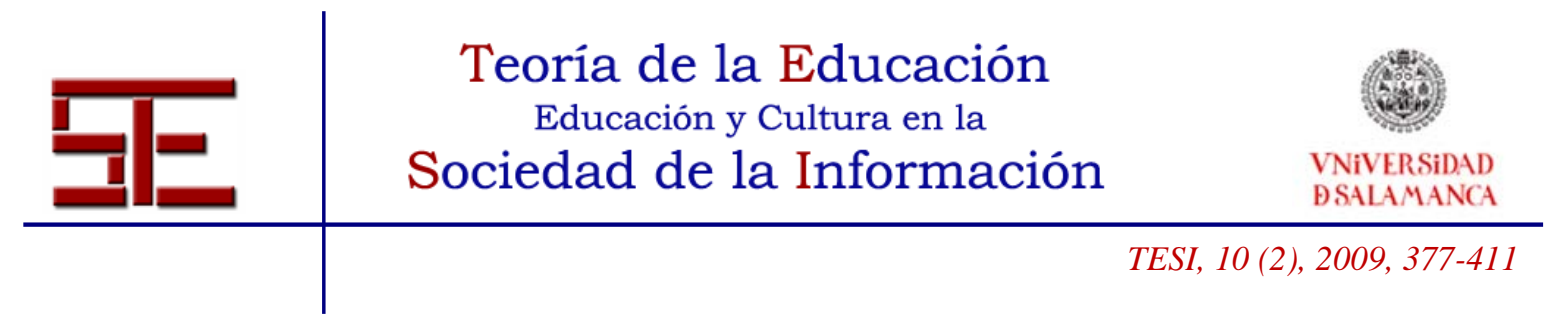

Figura 8. Uso de la mensajería instantánea

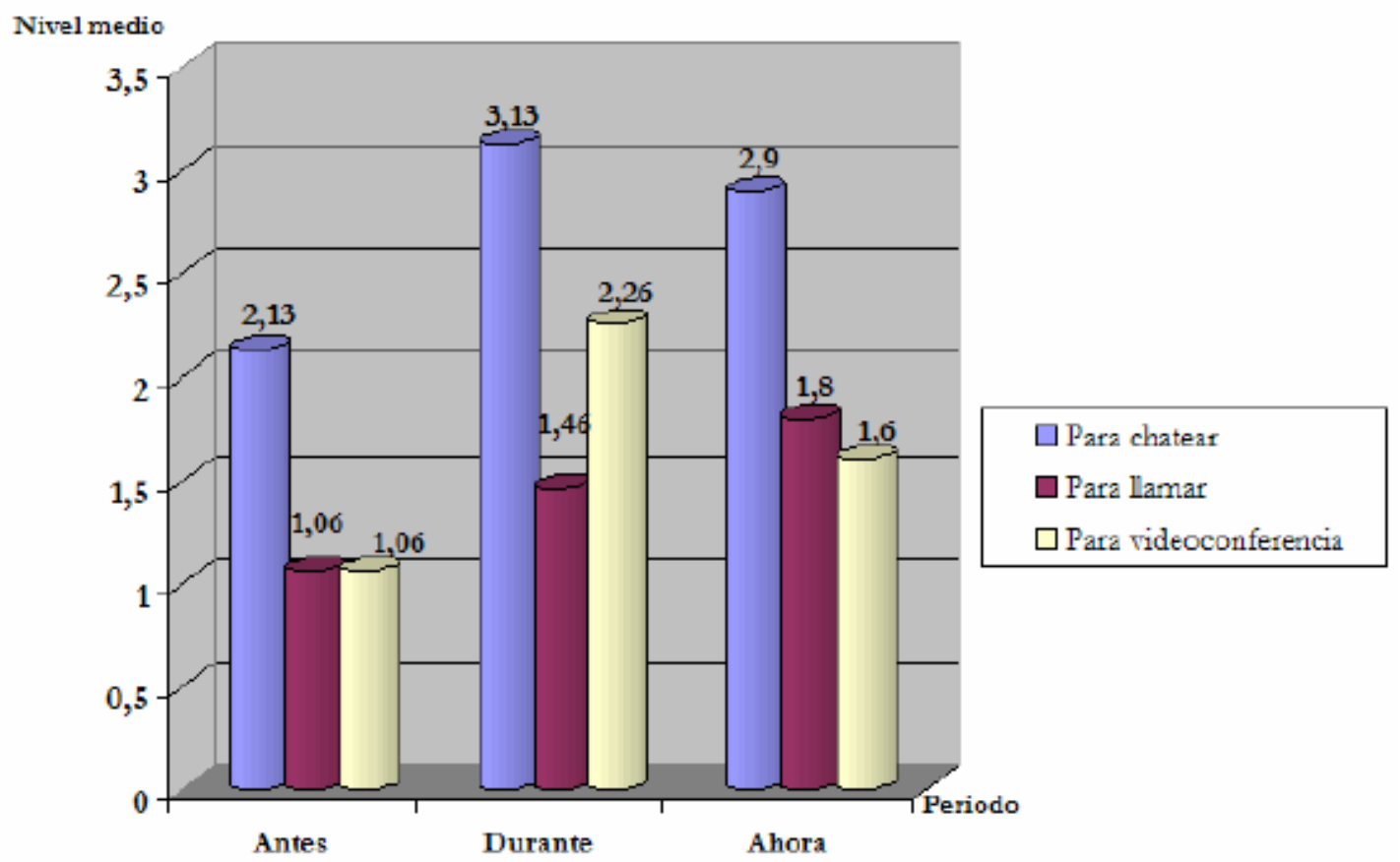

Fuente: elaboración propia

En la Figura 7 se expone el nivel medio, un valor que se basa en una escala del 1 al 5 (de menos a más) en relación a la frecuencia de uso de las actividades descritas en el cuestionario, en los periodos Antes, Durante y Ahora. Como se comprueba en el gráfico, el nivel máximo (5) no lo ha alcanzado ninguna de las actividades en la red.

Cabe decir que la mayoría de actividades relacionadas con la comunicación y con la búsqueda de información han experimentado una evolución creciente desde el periodo anterior a la estancia en el extranjero hasta ahora.

En la Figura 8 se presenta un gráfico relativo a la frecuencia de Uso de la mensajería instantánea (1 al 5): para chatear, para llamar y para videoconferencia. Por lo general, se comprueba que en todos los periodos los informantes usan principalmente la mensajería instantánea con el fin de chatear. Cabe decir que el uso de la mensajería

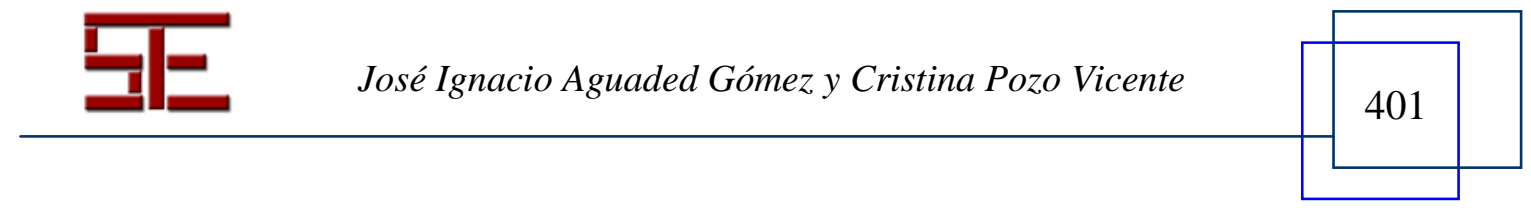




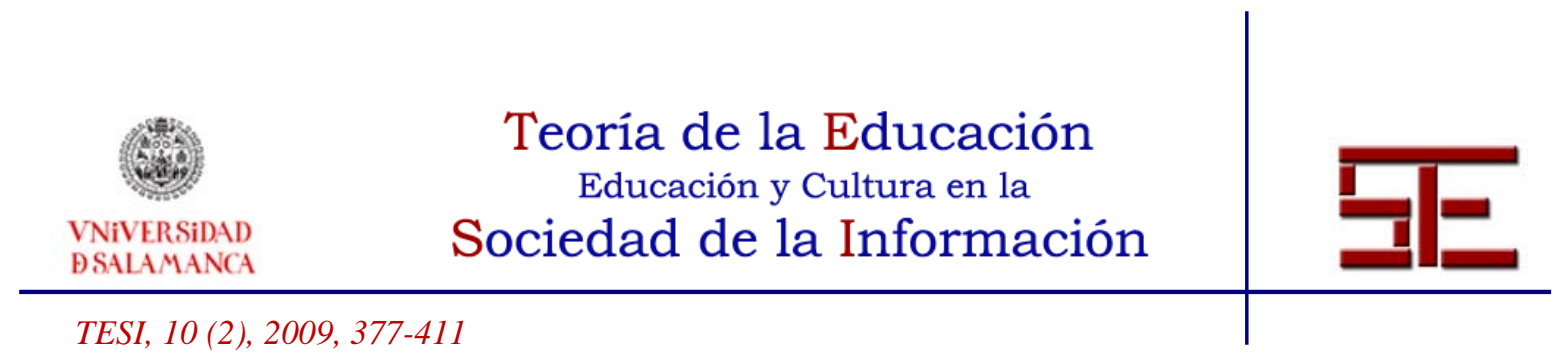

instantánea para chatear presenta su ápice durante el periodo de estancia en el extranjero, mostrando un crecimiento puntual del 1, con respecto a Antes.

Figura 9. Lengua de búsqueda de información

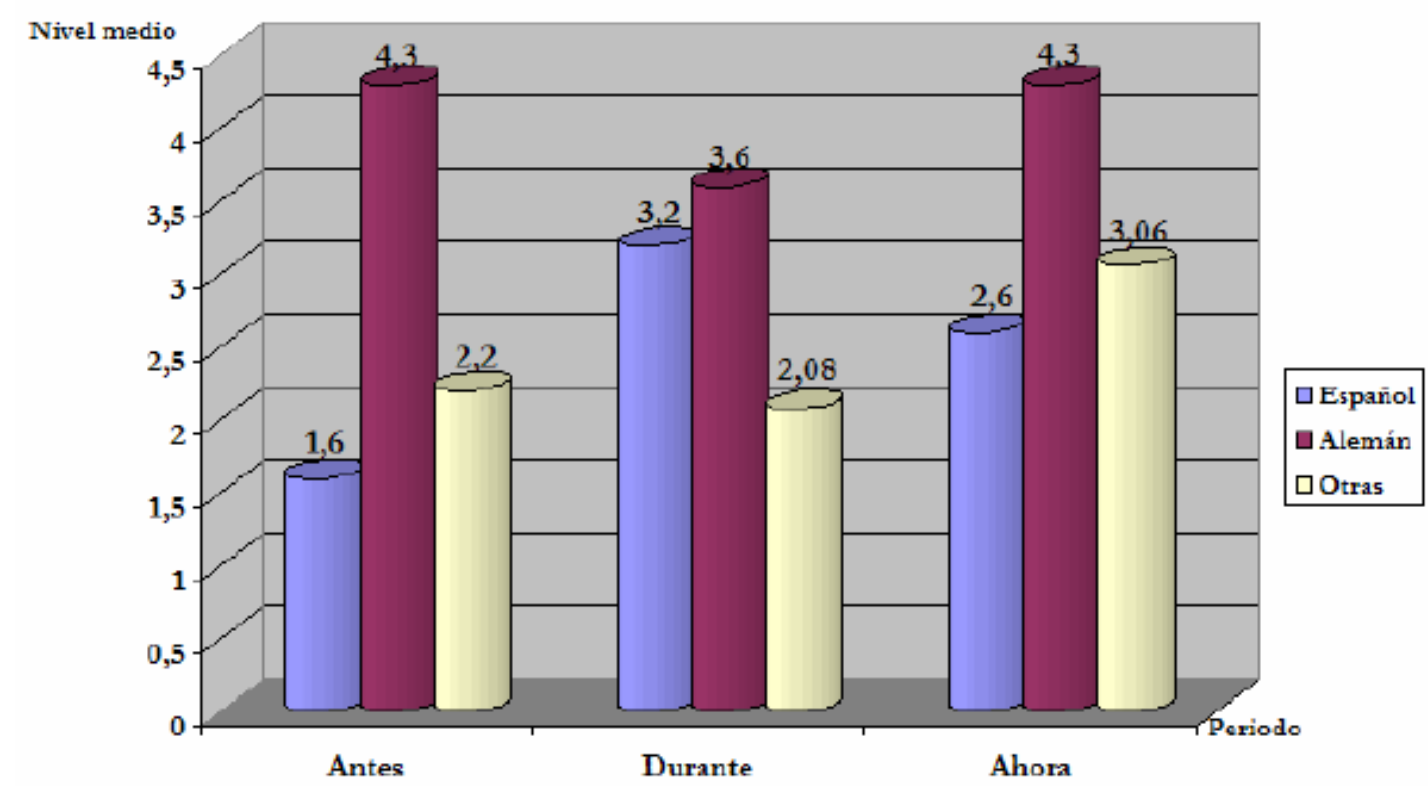

Fuente: elaboración propia

En la Figura 9, se observa como el uso en la red de la lengua materna para la búsqueda de cualquier tipo de información es el predominante en la mayoría de los periodos, es decir, el alemán. Aún así, es importante analizar la evolución del uso de las diferentes lenguas como código de búsqueda de información en los diferentes periodos. En Antes, la lengua de comunicación en la red para los informantes era principalmente el alemán. En Durante, el idioma más empleado para la búsqueda en la red siguió siendo el alemán, pero cabe destacar que presenta una pérdida de 0,7 puntos respecto al periodo Antes. En ese periodo, el español es la lengua que percibe un mayor crecimiento 1,6, el cual pasa por delante de otras lenguas. Sin embargo, en el periodo Ahora, el alemán recupera su frecuencia de uso y se sitúa en una frecuencia de uso igual al periodo anterior a la estancia en el extranjero.

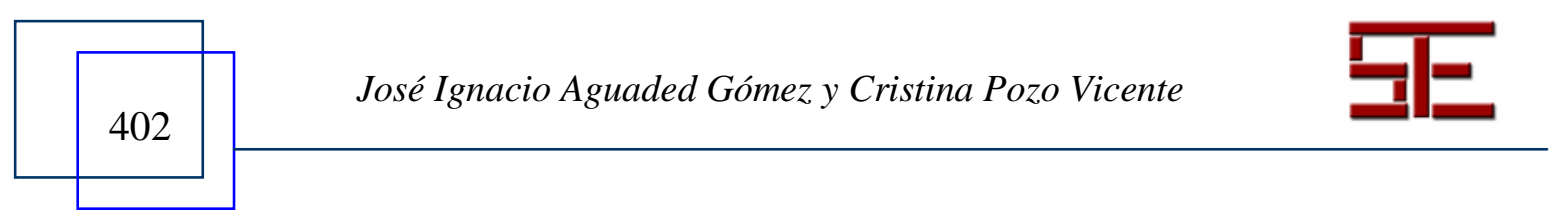




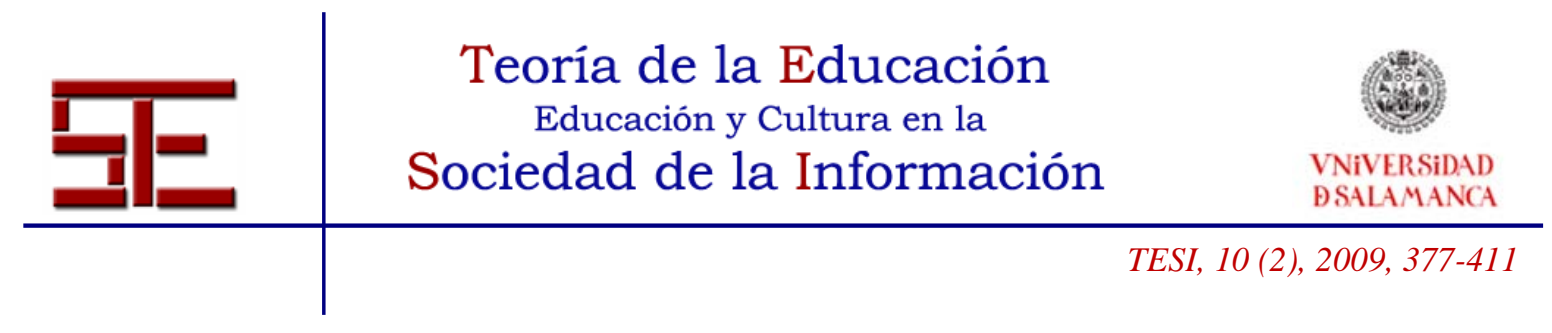

Figura 10. Lengua de comunicación

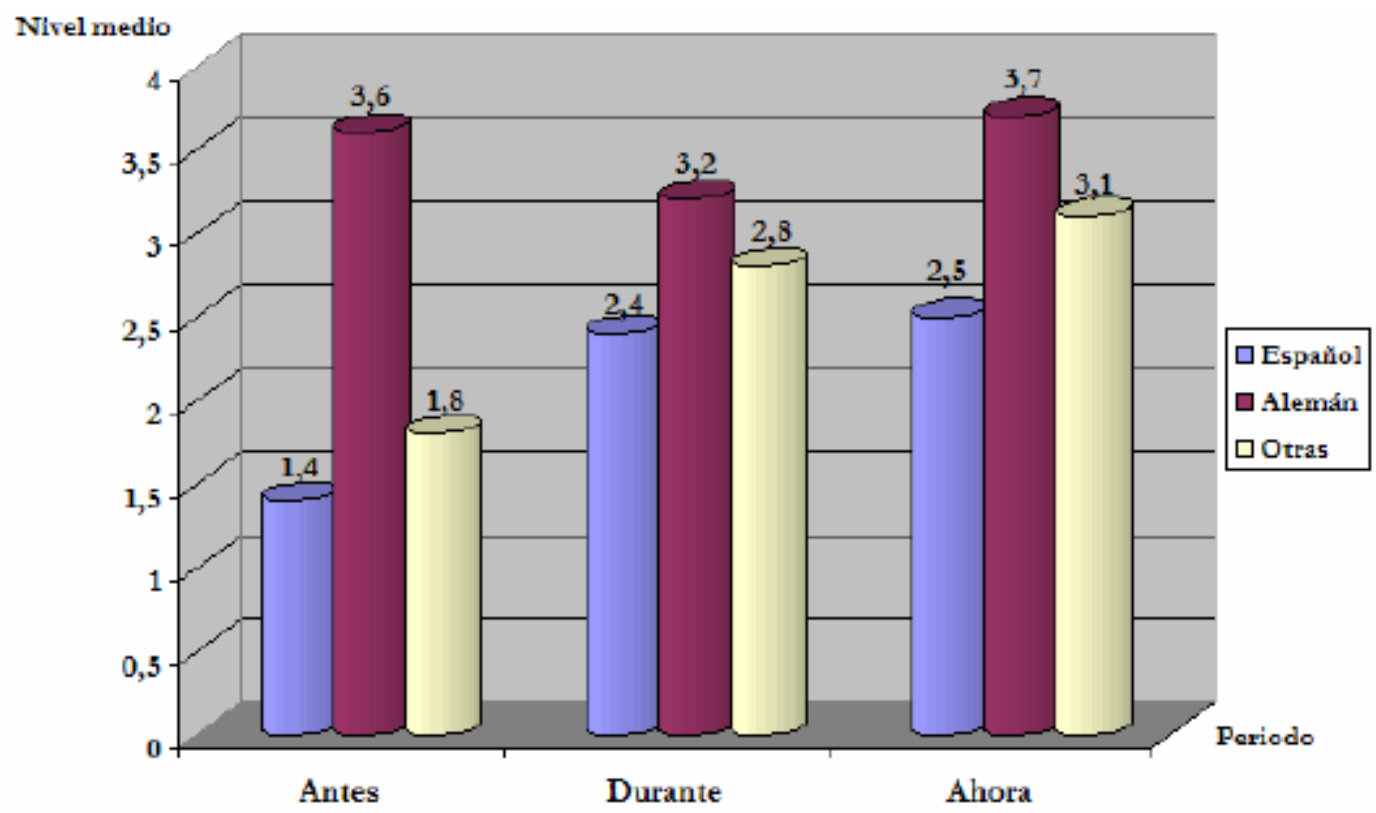

Fuente: elaboración propia

Las lenguas principales de comunicación en la red son: el español, el alemán y otras.

Como en la Figura 9 y en la Figura 10, el alemán es el idioma que muestra una mayor frecuencia de uso como la lengua habitual de comunicación de los informantes en la red. Sin embargo, es interesante destacar el crecimiento experimentado en el periodo

Durante y Ahora del uso del español y de otras lenguas en la comunicación de los informantes en la red respecto a Antes, siendo el empleo de otras lenguas superior al uso del español en la comunicación en la red en ese periodo.

En cuanto a los valores relacionados con el conocimiento y la capacidad de usar sistemas informáticos resultaron no ser significativos para nuestro estudio, ya que tanto en el periodo antes y después del Erasmus las cifras eran similares. Por ello, no nos parece relevante abarcarlo en este artículo.

\section{RESULTADOS}

\subsection{Competencias comunicativas}

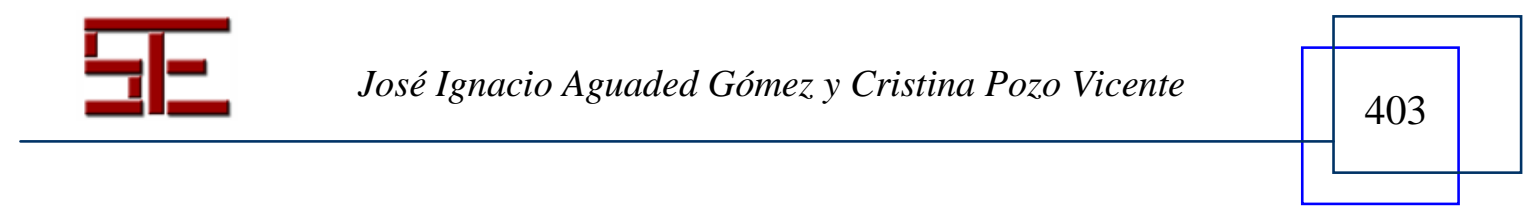




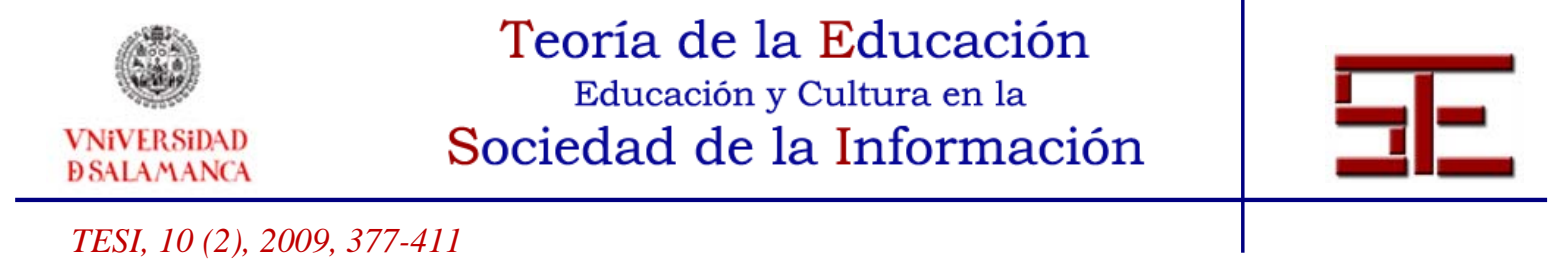

La mejora de los niveles de competencias comunicativas de los informantes es una realidad y así lo representan los gráficos correspondientes a la comparación de los niveles de competencias de Antes y Ahora. De esa forma, se constata una evolución a nivel global en todas las competencias comunicativas tras la estancia en el extranjero.

Como se puede observar en los gráficos del apartado (2.4.), las competencias que han presentado una mayor desviación típica y, por lo tanto, que han mostrado una mayor diferencia entre los niveles de los informantes en el periodo Antes son básicamente competencias de carácter oral, mientras que en Ahora, las diferencias entre niveles se refieren a competencias de carácter escrito.

Si las diferencias entre los niveles en competencias de carácter oral de los informantes son menores tras la estancia en el extranjero, podemos pensar que en esa etapa el aprendizaje de la lengua tiene lugar esencialmente en contextos reales que superan el aula, contextos en los que la actividad principal y más habitual es la comunicación oral. Asimismo, la estancia en el extranjero se presenta como una oportunidad única para desarrollar y adquirir un elevado nivel de competencia comunicativa, independientemente del nivel anterior a la estancia, y que los niveles entre los estudiantes Erasmus se mejoran y se equiparan, sobre todo, en las competencias de carácter oral (Comprensión auditiva, Expresión oral e Interacción oral).

En cuanto al número de lenguas en contacto, cabe destacar que los informantes afirmaron haber entrado en contacto con un gran número de lenguas, sobre todo, europeas, dado que la mayoría de estudiantes que participan en el proyecto Erasmus proceden de universidades de la Unión Europea. Eso confirma que la estancia en el extranjero es un escenario que fomenta el plurilingüismo.

\subsection{Competencias telemáticas}

En cuanto a las competencias telemáticas no se puede afirmar de forma categórica una evolución en las competencias referentes a los sistemas operativos, a los programas básicos y al uso de internet, ya que el aumento es casi inapreciable. Pero sí hay otros aspectos que han mejorado significativamente entre el periodo Antes y el Ahora, tal y como se exponen a continuación.

Los informantes se han habituado a utilizar la navegación en la red como medio de comunicación y búsqueda de información. Respecto al periodo Antes el crecimiento ha

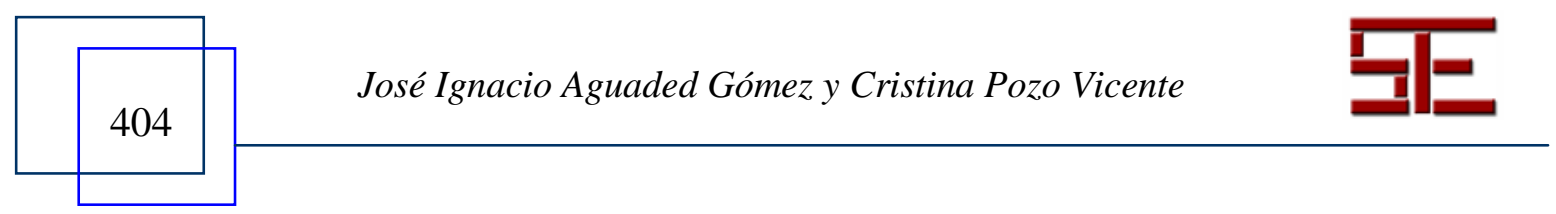




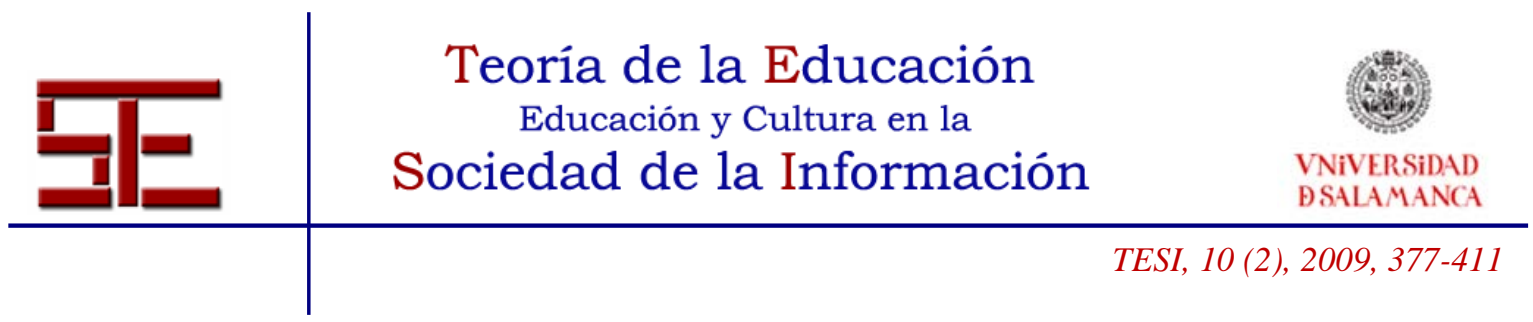

sido notable, sobre todo, en la consulta de páginas web y en el uso del correo electrónico y de buscadores.

El uso de la mensajería instantánea se utilizó básicamente para chatear y presenta un crecimiento significativo durante el periodo Durante, al igual que la videoconferencia.

En cuanto a la búsqueda de información, la lengua más empleada en todos los periodos es el alemán -lengua materna de los informantes. No obstante, durante la estancia en el extranjero de los estudiantes de la muestra, el español es la lengua más utilizada para buscar información, creciendo de manera notable en su uso.

A pesar de que la lengua de comunicación y búsqueda de información de los informantes en la red en todos los periodos es el alemán, el español y otras lenguas muestran un incremento como códigos de búsqueda de información y de comunicación entre el periodos Antes y Ahora.

\section{CONCLUSIONES}

La finalidad de esta breve exposición de los resultados es comparar los resultados del estudio empírico con las hipótesis expuestas en la introducción del trabajo de investigación.

\subsection{Competencias comunicativas}

Los resultados de la investigación demuestran, en general, que los informantes han mejorado en todas las competencias comunicativas. En las preguntas abiertas algunos afirmaban: «mi español, en general, ha mejorado muchísimo durante mi estancia Erasmus en España. Antes, apenas podía hablar, entender o escribir español. Pues, he mejorado todas áreas». También confirman que la Interacción oral es la competencia que ha experimentado un mayor crecimiento, lo que puede interpretarse como que en un contexto real en el que se llevan a cabo principalmente actividades de carácter oral, los informantes han adquirido en el intercambio comunicativo una mayor espontaneidad, flexibilidad y fluidez. Por lo tanto, ese contexto propicia el aprendizaje y la adquisición de competencias como la expresión y la comprensión oral.

En cuanto al uso en el contexto real de conocimientos lingüísticos y habilidades comunicativas adquiridos en el aula, sobre todo, relativos a la expresión oral y la

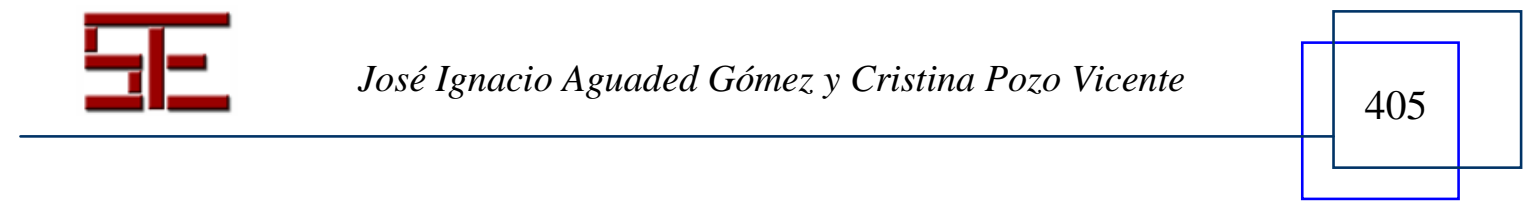




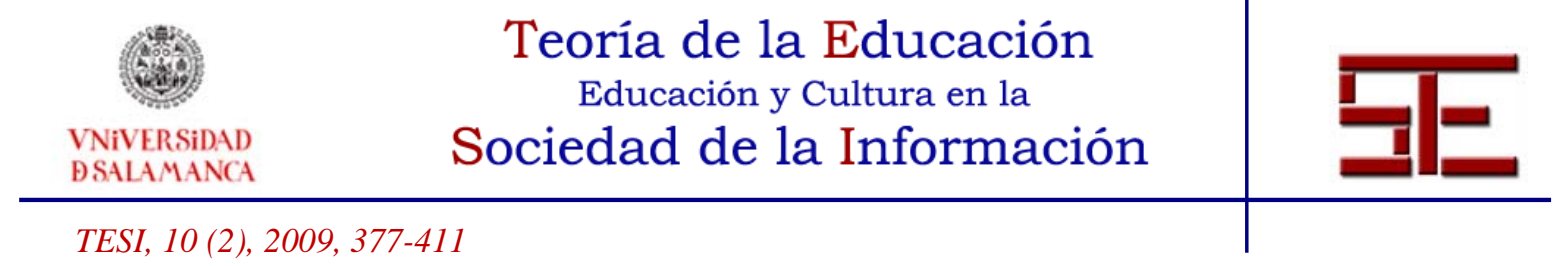

comprensión oral y lectora, los mismos informantes en las preguntas abiertas expresaron que durante su estancia en el extranjero emplearon los conocimientos, hasta entonces «pasivos», adquiridos en las clases de lengua extranjera: «durante el Erasmus empecé a hablar y a escuchar español. Antes, había ido a clases de español en la universidad, pero aprendía español como una lengua muerta, concentrándome solo en la comprensión lectora y la expresión escrita». Ese aspecto se relaciona con la ampliación del léxico, sobre todo, de registro estándar y coloquial propio del lenguaje oral: «he ampliado mucho mis conocimientos de la lengua coloquial. Antes, mi nivel de lengua ya era notable pero a la hora de conversar me faltaba la confianza y la seguridad de hablar de forma libre y extensa».

El contacto con un gran número de lenguas (español, alemán, inglés, francés, italiano, portugués, búlgaro y finés) y el uso de lenguas como el español, el inglés y el catalán para comunicarse durante su estancia en España repercuten positivamente en la construcción de esquemas mentales basados en el plurilingüismo, es decir, aprender a pensar y a comunicarse en diferentes sistemas lingüísticos». También favorecen la adquisición de valores multiculturales como lo demuestran las opiniones de los informantes: «me lo influyó en mi punto de vista de idiomas y de la globalización en general. Estoy mucho más abierto e interesado en extranjeros y en vivir fuera de mi país» y «más que en lo lingüístico, creo que he mejorado mis competencias personales e internacionales».

Por lo tanto, en términos generales, se puede afirmar que las hipótesis referentes a las competencias comunicativas se verifican tras el análisis de los resultados de la investigación.

\subsection{Competencias telemáticas}

Los resultados de la investigación demuestran que la hipótesis que afirma que la estancia en el extranjero era un escenario óptimo para adquirir conocimientos básicos y avanzados sobre la red queda refutada, pues las competencias sobre el uso de internet son prácticamente las mismas en el periodo Antes y en el Ahora. Sin embargo, el estudio de las diferentes competencias como son el uso de los sistemas informáticos, de los sistemas operativos, de los programas básicos y de internet nos ha demostrado que los informantes tienen un mayor conocimiento de los usos de internet que de otras competencias.

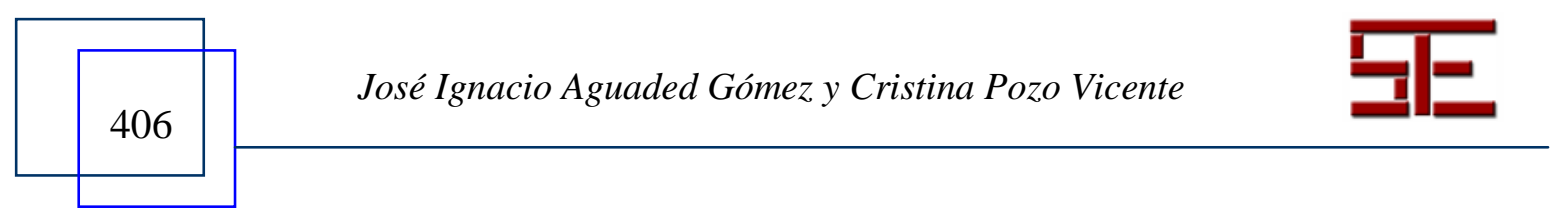




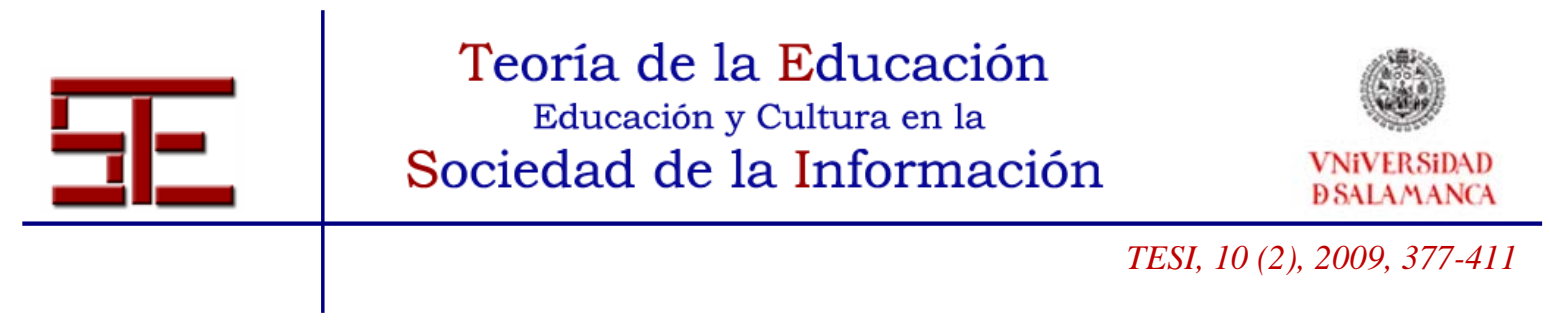

Resumiendo, la estancia Erasmus de los estudiantes genera un desarrollo de las competencias telemáticas, sobre todo, en el uso de la red, tal y como lo auguraban las hipótesis y lo confirman los resultados. Sin embargo, las competencias relacionadas con el uso de sistemas informáticos y operativos y con el uso de programas básicos manifiestan una tendencia de estancamiento, de lo que se puede deducir que la estancia en el extranjero no contribuye a mejorar las competencias telemáticas, en general, sino, en particular, al uso de internet para la comunicación y para la búsqueda de información y que además promueve relaciones humanas (redes sociales) y los intercambios lingüísticos en diferentes lenguas.

\section{REFERENCIAS}

AGENCIA NACIONAL DE EVALUACIÓN DE LA CALIDAD Y ACREDITACIÓN (2003). Programa de convergencia europea. El crédito Europeo. Madrid

(www.aneca.es/publicaciones/docs/publi_credito\%20europeo.pdf).

AGUADED, J.I. \& PÉREZ, M.A. (2001). Nuevas corrientes comunicativas, nuevo escenarios didácticos. Huelva. Comunicar, 16; 120-130.

ANDREA, S. (2000). «Internautas del idioma: ¿cómo desarrollar la competencia hipertextual de los adolescentes? " en Textos de Didáctica de la Lengua y de la Literatura,

$24 ; 59-72$.

BACHMAN, L. (1990). Fundamental considerations in language testing. Oxford: Oxford University Press.

BACHMAN, L. y PALMER, A. (1996). Language testing in practice. Oxford: Oxford University Press.

BISQUERRA, R. (1989). Método de investigación educativa. Barcelona: CEAC.

BRAUNER, D.J. \& VOLLMER, H.U. (1999). Erfolgreiches wissenschaftliches Arbeiten-Seminararbeit. Diplomarbeit und Doktorarbeit. Verlag Wissenschaft und Praxis.

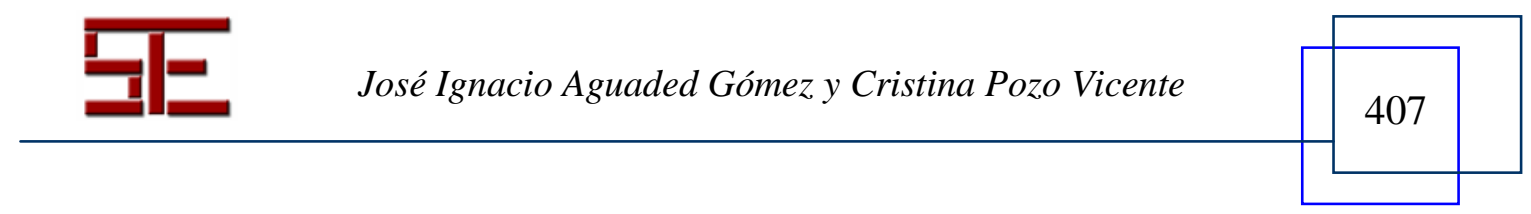




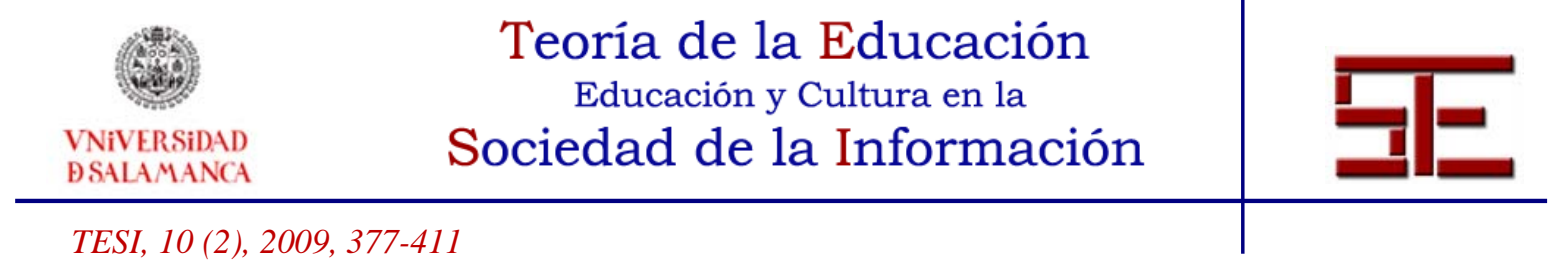

BUENDÍA, L.; COLÁS, P. \& HERNÁNDEZ, F. (1997). Métodos de investigación en psicopedagogía. Madrid: McGraw-Hill.

CABERO, J. y HERNÁNDEZ, M. J. (1995). Utilizando el vídeo para aprender. Una experiencia con los alumnos de magisterio. Sevilla: Secretariado de Recursos Audiovisuales y Nuevas Tecnologías de la Universidad de Sevilla.

CANALE, M. (1983). «From Communicative Competence to Communicative Language Pedagogy», Language and Communication, en RICHARDS, J. Y SCHMIDT, R. (Eds.). London.

CANALE, M. \& SWAN, M. (1980). Theoretical bases of communicative approaches to second language teaching and testing. Applied Linguistics.

CANDLIN, C.N. (1986). Explaining communicative competence limits of testability, en CARRASCO, A.; GRACIA, E. \& DE LA IGLESIA, C. (2005). Las TIC en la construcción del espacio europeo de educación. Revista Iberoamericana de Educación.

CARROLL, J. B. (1963). A model of school learning. Teachers College Record, 64; 723-733.

CARROLL, J.B. (1968). On learning from being told. Educational Psychologist, 5; 410.

CASALS, P. \& LORENZO, N. (1997). «Nuevas estrategias para la didáctica de las lenguas extranjeras asistidas por ordenador en las redes telemáticas» en CANTERO,

F.; MENDOZA, A. Y ROMEA, C. (Eds.). Didáctica de la Lengua y la Literatura para una sociedad plurilingüe del siglo XX. Barcelona: Universidad de Barcelona:

1141-1146.

COHEN, L. \& MANION, L. (1989). Research Methods in Education. London: Routledge.

COLL, C. (1999). La concepción constructivista como instrumento para el análisis de las prácticas educativas escolares en COLL, C. (Coord.). Psicología de la instrucción: la enseñanza y el aprendizaje en la educación secundaria. Barcelona: ICE/UB-Horsi.

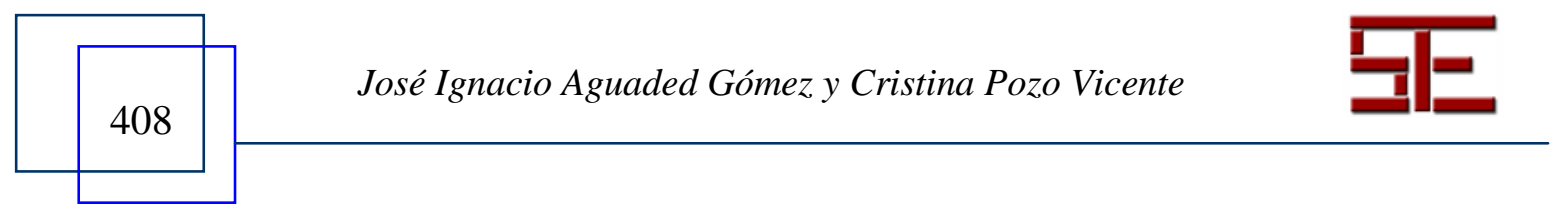




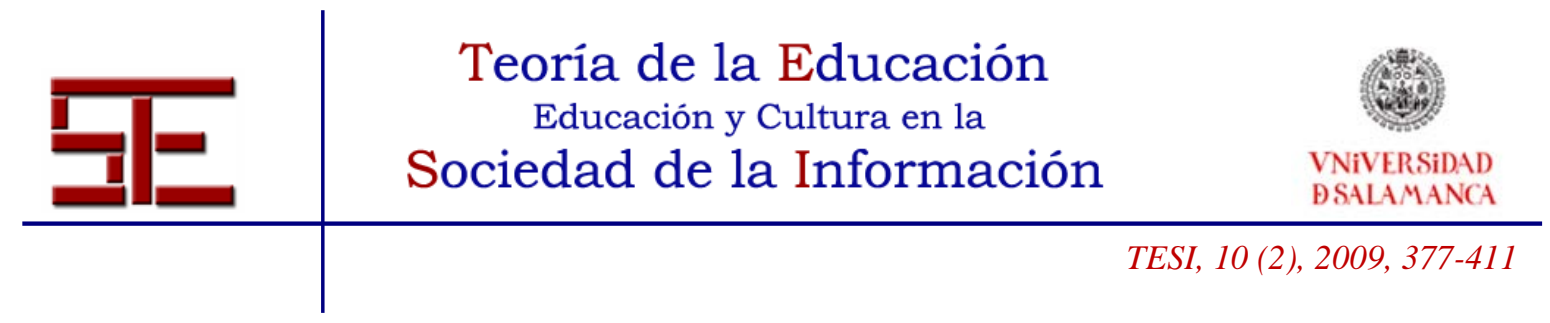

COMISIÓN DE LAS COMUNIDADES EUROPEAS (2006). El marco europeo de calificaciones, una nueva herramienta para entender las calificaciones en toda Europa (http://ec.europa.eu/education/policies/educ/eqf/-index_en.html).

COMISIÓN DE LAS COMUNIDADES EUROPEAS (2006). Recomendación del Parlamento Europeo y del Consejo relativa a la creación del Marco Europeo de Calificaciones para el aprendizaje permanente. Propuesta de la Comisión. Bruselas, 5 de septiembre de 2006 (http://europa.eu/rapid/pressReleases Action.do?reference=IP/ 06/1148\&.format $=P D F \&$ aged $=0$ \&language $=E S-\&$ guiLanguage $=e n)$.

COMISSION OF THE EUROPEAN COMMUNITIES (2003). Promoting Language Learning and Linguistic Diversity: An Action Plan 2004 - 2006. Brussels (http://ec.europa.eu/education/doc/official/keydoc/actlang/- act_lang_en.pdf).

CONSEJO DE EUROPA. Convenio sobre reconocimiento de calificaciones relativas a la educación superior en la región europea. Lisboa, 11 de abril de 1997, en www.bologna-berlin2003.de/pdf/Lisbon_convention.pdf.

CONSEJO DE EUROPA. Suplemento Europeo al Título, 19 de septiembre de 2002 (www.ub.es/biologia/agaur/documents/docs_ministeri_generalitat/suplementoeuropeo.p df).

DELORS, J. (1996). La educación a lo largo de la vida. La educación encierra un tesoro. México, UNESCO.

ENGEL, S. \& PREIßER, A. (2001). Promotionsratgeber. München-Wien, Oldenbourg Verlag.

Europe. Bilbao, Universidad de Deusto-Universidad de Groningen, en

www.relint.deusto.es/TUNINGProject/spanish/doc_fase1/Tuning\%20Edu -cational.pdf.

EUROPEAN COMMISION (2007). Education and Training (http://ec.europa.eu/ education/index_en.html).

GONZÁLEZ, J. \& WAGENAAR, R. (2003). Tuning Educational Sructures in Europe. Informe final Fase 1. Bilbao, Universidad de Deusto.

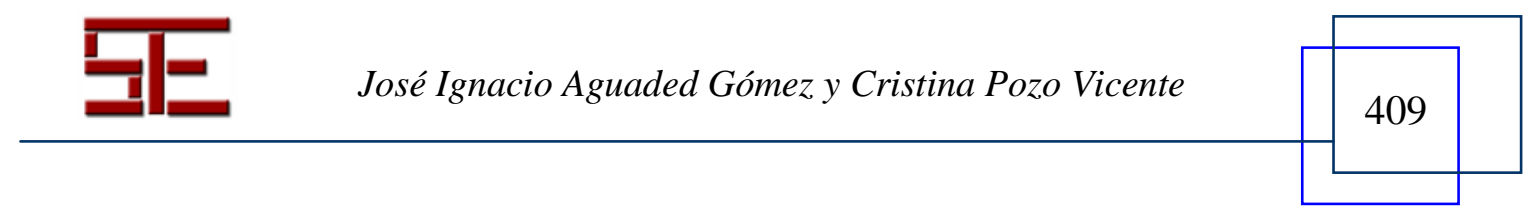




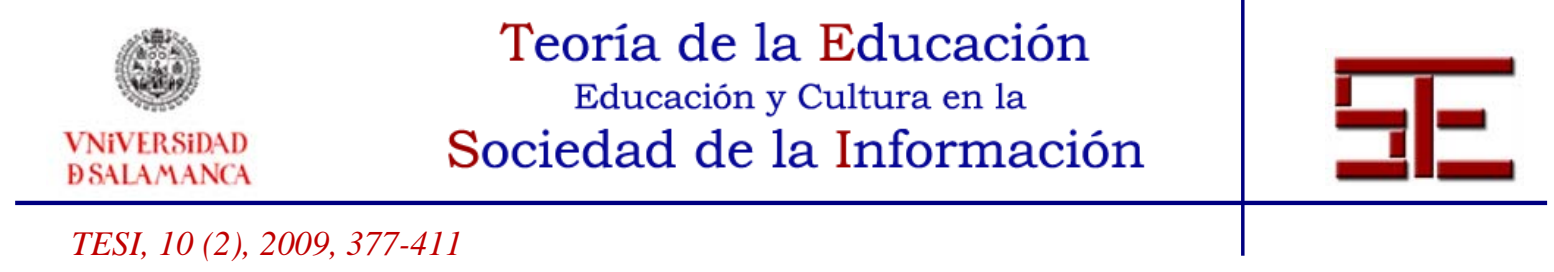

GRICE, H.P. (1976). Logic and Conversation, en COLE, P. \& MORGAN, J. (Eds.). Syntax and Semantics: Speech Acts. Nueva York: Academic Press; 41-58.

GUNZERHÄUSER, R. \& HAAS, E. (2002). Promovieren mit Plan- Ihr individueller Weg: von der Themensuche zum Doktortitel. Frankfurt A.M., Verlag Barbara Budrich UTB.

HALLIDAY, M.A. (1976). "A Brief Sketch of Systemic Grammar», in Kress, G.R. (Eds.), System and Function in Language, London: Oxford University Press; 3-6.

HATCH, E. \& LONG, M.H. (1980). Discourse Analysis, what's that? In LARSENFREEMAN, D. (Ed.). Discourse Analysis in Second Language Research. Rowley, Mass. Newbury House.

HYMES, D. (1972). Reinventing Anthropology. New York: Pantheon.

HYMES, D. (1974). Foundations in Sociolinguistics: An Ethnographic Approach. Phiadelphia: University of Pennsylvania Press.

HYMES, D. (1983). Studies in the History of Linguistic Anthropology. Amsterdam: John Benjamins.

KERLINGER, F.N. (1985). Enfoque conceptual de la investigación del comportamiento. México: Interamericana.

KRAMSCH, C. (1983). "Culture and constructs: Communicating attitudes and values in the foreign language classroom”, Foreign Language Annals, 16/6.

LADO, R. (1961). Language Testing: The construction and use of Foreign Language Tests. New York: Mcgraw-Hill.

MESSING, B. y HUBER, K.P. (2000). Die Doktorarbeit: Vom Star zum Ziel. Heidelberg: Springer.

MUNBY, J. (1978). Communicative Syllabus Design. Cambridge.

PÉREZ, M.A. \& AGUADED, J.I. (1994). ¿Cómo enseñar y aprender la actualidad?

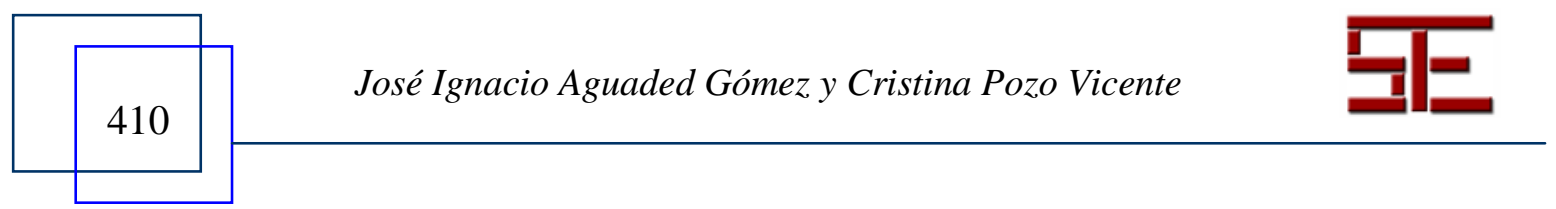




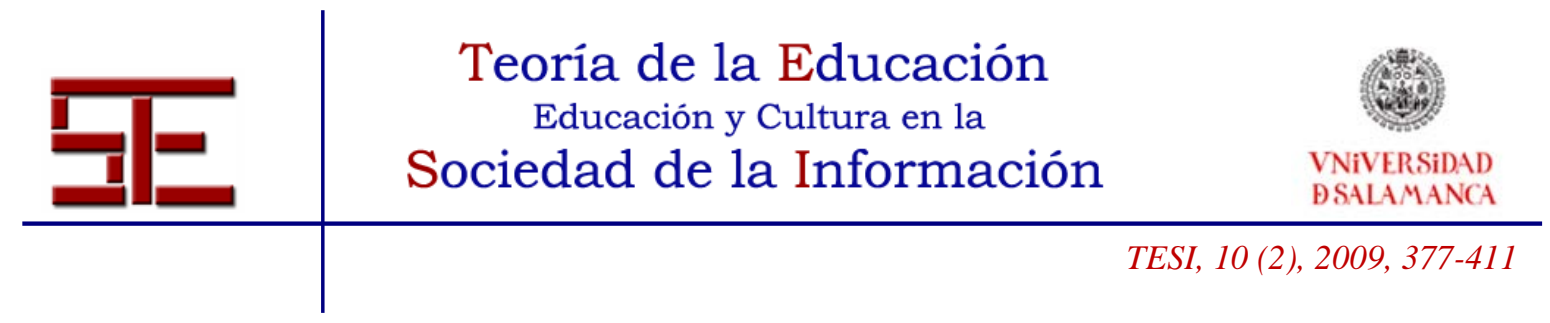

Huelva. Grupo Pedagógico Andaluz «Prensa y Educación».

PRADO ARAGONÉS, J. (2001). La competencia comunicativa en el entorno tecnológico: desafío para la enseñanza. Huelva, Comunicar, 17; 21-30.

RODRÍGUEZ, G. \& AL. (1996). Metodología de la investigación cualitativa. Málaga: Aljibe.

RODRÍGUEZ LÓPEZ, J.M. (2002). La evaluación en la Universidad. La evaluación del aprendizaje de los alumnos universitarios, en MAYOR, C. (Coord.). Enseñanza y aprendizaje en la Educación Superior. Barcelona, Octaedro.

SAVIGNON, S.J. (1983). Communicative Competence: Theory and Classroom Practice. Texts and Contexts in Second Language Learning, Reading.

SEARLE, J.R. (1969). Speech Acts: An Essay in the Philosophy of Language. Cambridge, Cambridge University Press. University Press.

VAN DIJK, T.A. (1977). Text and Context: Explorations in the semantincs and pragmatics of Discourse. London, Longman.

WIDDOWSON, H.G. (1983). Learning purpose and language use. Oxford: Oxford University Press.

Para citar la presente editorial puede utilizar la siguiente referencia:

Aguadez Gómez, J.I. y Pozo Vicente, C. (2009). Los alumnos Erasmus en la torre de babel. El aprendizaje de lenguas extranjeras basado en las competencias comunicativas y en el uso de las TIC, en Ortega Sánchez, I. y Ferrás Sexto, C. (Coord.) Alfabetización Tecnológica y desarrollo regional. Revista Electrónica Teoría de la Educación: Educación y Cultura en la Sociedad de la Información. Vol. 10, $n^{\circ} 2$. Universidad de Salamanca, pp. 377-411 [Fecha de consulta: dd/mm/aaaa].

http://campus.usal.es/ revistas_trabajo/index.php/revistatesi/article/view/7522/7555

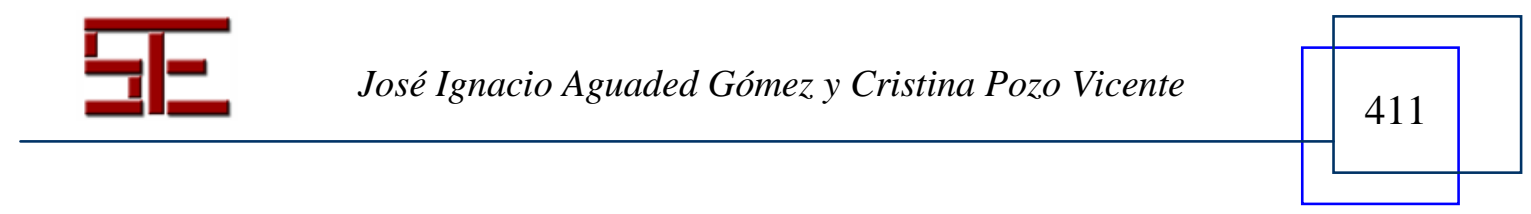

